ARTICLE

Check for updates

https://doi.org/10.1038/s41467-020-15608-y

\title{
Targeting codon 158 p53-mutant cancers via the induction of p53 acetylation
}

Li Ren Kong (1,2凶${ }^{\text {, }}$, Richard Weijie Ong ${ }^{3}$, Tuan Zea Tan (10 1, Nur Afiqah Binte Mohamed Salleh', Matan Thangavelu4, Jane Vin Chan ${ }^{4}$, Lie Yong Judice Koh ${ }^{4}$, Giridharan Periyasamy ${ }^{4}$, Jieying Amelia Lau', Thi Bich Uyen Le ${ }^{3}$, Lingzhi Wang1,5, Miyoung Lee ${ }^{2}$, Srinivasaraghavan Kannan (1) ${ }^{6}$, Chandra S. Verma ${ }^{6,7,8}$, Chwee Ming Lim ${ }^{9}$, Wee Joo Chng 1,10,11, David P. Lane (1) ${ }^{12}$, Ashok Venkitaraman², Huynh The Hung ${ }^{3}$, Chit Fang Cheok ${ }^{13,14,15}$ \& Boon Cher Goh (1) 1,5,10凶

Gain of function (GOF) DNA binding domain (DBD) mutations of TP53 upregulate chromatin regulatory genes that promote genome-wide histone methylation and acetylation. Here, we therapeutically exploit the oncogenic GOF mechanisms of p53 codon 158 (Arg ${ }^{158}$ ) mutation, a DBD mutant found to be prevalent in lung carcinomas. Using high throughput compound screening and combination analyses, we uncover that acetylating mutp53R158G could render cancers susceptible to cisplatin-induced DNA stress. Acetylation of mutp53R $158 \mathrm{G}$ alters DNA binding motifs and upregulates TRAIP, a RING domain-containing E3 ubiquitin ligase which dephosphorylates $І_{\kappa} B$ and impedes nuclear translocation of RelA (p65), thus repressing oncogenic nuclear factor kappa-B (NF-KB) signaling and inducing apoptosis. Given that this mechanism of cytotoxic vulnerability appears inapt in p53 wild-type (WT) or other hotspot GOF mutp53 cells, our work provides a therapeutic opportunity specific to Arg ${ }^{158}$-mutp53 tumors utilizing a regimen consisting of DNA-damaging agents and mutp53 acetylators, which is currently being pursued clinically.

\footnotetext{
${ }^{1}$ Cancer Science Institute of Singapore, National University of Singapore, Singapore 117599, Singapore. ${ }^{2}$ Medical Research Council Cancer Unit, University of Cambridge, Cambridge CB2 OXZ, UK. ${ }^{3}$ Laboratory of Molecular Endocrinology, National Cancer Centre Singapore, Singapore, Singapore. ${ }^{4}$ Genome Institute of Singapore, Agency for Science, Technology \& Research (A*STAR), Singapore 138672, Singapore. ${ }^{5}$ Department of Pharmacology, Yong Loo Lin School of Medicine, National University of Singapore, Singapore 117597, Singapore. ${ }^{6}$ Bioinformatics Institute, Agency for Science, Technology, and Research (A*STAR), Singapore 138671, Singapore. ${ }^{7}$ Department of Biological Sciences, National University of Singapore, Singapore 117558, Singapore. ${ }^{8}$ School of Biological Sciences, Nanyang Technological University, Singapore 639798, Singapore. ${ }^{9}$ Division of Surgical Oncology (Head and Neck Surgery), National University Cancer Institute, Singapore (NCIS), Singapore 119074, Singapore. ${ }^{10}$ Department of Haematology-Oncology, National University Cancer Institute, Singapore 119074, Singapore. ${ }^{11}$ Department of Medicine, Yong Loo Lin School of Medicine, National University of Singapore, Singapore 119228 , Singapore. ${ }^{12}$ p53 Laboratory (p53Lab), Agency for Science, Technology, and Research (A*STAR), Singapore 138648, Singapore. ${ }^{13}$ Institute of Molecular and Cell Biology (IMCB), Agency for Science, Technology, and Research (A*STAR), Singapore 138673, Singapore. ${ }^{14}$ Department of Pathology, Yong Loo Lin School of Medicine, National University of Singapore, Singapore 119074, Singapore. ${ }^{15}$ Department of Biochemistry, Yong Loo Lin School of Medicine, National

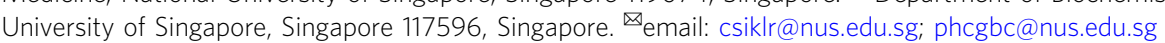




\section{$T$} P53 missense mutations are among the most common genetic lesions in tumors ${ }^{1}$, which often coincide with the earlier onset of oncogenesis than patients with p53 loss ${ }^{2}$. A single nucleotide substitution at the DNA-binding domain (DBD) renders the protein defective in DNA-binding, loss of tumor suppressive properties and concomitantly prevents the negative feedback regulation through $\mathrm{MDM}^{3,4}$, leading to massive accumulation of full length mutant p53 (mutp53). Growing evidence from recent studies suggest that cells with prevalent mutp53 acquire additional oncogenic gain-of-function (GOF) based on their unique structural modifications ${ }^{5-8}$. Depletion of mutp53 or inhibition of its co-activator have demonstrated strong cytotoxicity in tumor cells $\mathrm{s}^{6,9,10}$.

Proposed oncogenic mechanisms of hotspot p53 mutations include prolonged tumor necrosis factor alpha (TNF- $\alpha$ ) signaling through the activation of $\mathrm{NFkB}$ (nuclear factor kappa-lightchain-enhancer of activated B cells $)^{11,12}$, causing chronic tumorassociated inflammation, as well as altered structural interaction between mutated p53 and DNA that induces transcriptional perturbations to promote tumor-associated gene expression ${ }^{13-15}$. Data derived from The Cancer Genome Atlas (TCGA) reveal a specific point mutation on arginine codon $158\left(\mathrm{Arg}^{\mathrm{R} 158}\right)$ to be a recurrent mutation in lung carcinomas (16 out of 742 specimens) ${ }^{16-19}$. In contrast to the other well-established hotspot mutp537,8,20-23, the functional aspects of this mutation have not been well-characterized.

In this study, we uncover a mechanism of activating mutp53dependent apoptotic function in cancer cells through p53 $2158 \mathrm{G}$ acetylation, and demonstrate that TRAIP regulation of $\mathrm{NFkB}$ is the main molecular driver underpinning this observed sensitivity. We further show in a high-throughput screen that acetylation of p53 ${ }^{\mathrm{R} 158 \mathrm{G}}$ can be achieved with several pharmacologic agents, providing a cogent basis for further clinical development.

\section{Results}

GOF p53 $^{\text {R158G }}$ confers differential drug sensitivity. Among the TP53 mutations found in $~ 50 \%$ of non-small cell lung cancer ${ }^{24}$, $\mathrm{p} 53^{\mathrm{R} 158 \mathrm{G} / \mathrm{H} / \mathrm{L}}$ is one of the most common mutation hotspots according to multiple public databases (TCGA, COSMICS, IARC p53 Database), despite being reported in different frequencies ${ }^{25}$. Further TCGA analysis on sequencing of 742 lung cancer patients showed a frequency of $4.5 \%(n=8)$ and $1.4 \%(n=8)$ in LUSC $(n=178)$ and adenocarcinoma (LUAD, $n=564)$ subtypes, respectively (Supplementary Fig. 1A, Supplementary Table 1). In addition, the frequency of codon 158 was found to be comparable to other hotspot mutp53 in both lung cancer subtypes (Supplementary Table 2). H2170 LUSC cells that are homozygous for p53 $158 \mathrm{G}$ (Supplementary Fig. 1B) demonstrated impaired MDM2 and CDKN1A transactivation when treated with Nutlin3a, a MDM2 antagonist, as compared to MRC5 (p53wt) cells, indicating loss of p53 function (Supplementary Fig. 1I). To gain better insights into the $\mathrm{p} 53^{\mathrm{R} 158 \mathrm{G}}$ function, we generated isogenic cell-lines expressing either wild-type (p53 $3^{\mathrm{wt}}$ ) or mutant $\left(\mathrm{p} 53^{\mathrm{R} 158 \mathrm{G}}\right) \mathrm{p} 53$ from homozygous deleted LUSC Calu-1 cells $\left(\mathrm{p} 53^{-1-}\right)$. As forced expression of WT p53 could induce cytotoxicity, we verified the presence of full length TP53 in each isolated stable clones (Supplementary Fig. 1C-H). As expected, expression of wild-type p53 (wtp53) increased transcription of MDM2, CDKN1A, PUMA, and PMAIP1 transcripts compared to p53-I- cells; in p53 ${ }^{\mathrm{R} 158 \mathrm{G}}$ cells, elevated CDKN1A showed partial preservation of $\mathrm{p} 53$ function, but reduced PMAIP1 transcription indicated gain of alternative function (Supplementary Fig. 1J-M). Functionally, mutp $53^{\mathrm{R} 158 \mathrm{G}}$ overexpression significantly increased cellular motility (Fig. 1a, b) as well as anchorage-independent colony formation (Fig. 1e, f); whereas invasiveness of $\mathrm{H} 2170$ cells could be reduced with TP53 knockdown (Fig. 1c, d). In contrast, overexpression of wtp53 exerted strong tumor suppressive effects in Calu-1 cells by reducing invasiveness (Fig. 1a, b) with no apparent colony growth. Importantly, xenograft tumors derived from $\mathrm{p} 53^{\mathrm{R} 158 \mathrm{G}}$ cells demonstrated more aggressive growth relative to those from $\mathrm{p} 53^{-/-}$and $\mathrm{p} 53^{\mathrm{wt}}$ cells (Fig. $1 \mathrm{~g}, \mathrm{~h}$ ), consistent with the oncogenic GOF described in other hotspot variants $10,22,26$.

Understanding the mechanisms underlying mutp53 GOF has allowed for anti-tumoral strategies aimed at inhibiting the oncogenic attributes of mutp536,9,10,27-29. Accordingly, we screened isogenic Calu-1 cell-lines through high-content compound screening (Supplementary Table 3), and quantifying the relative cell viability after single drug treatment at 0.1 or $1 \mu \mathrm{M}$, respectively. We first selected for compounds that showed efficacy (> 50\% growth inhibition) in at least one cell type (Supplementary Table 3 ), and identified inhibitors specific to $\mathrm{p} 53^{-l-}$, p $53^{\mathrm{wt}}$, and p53 ${ }^{\mathrm{R} 158 \mathrm{G}}$ cell-lines (Fig. 2a, Supplementary Fig. 2A, B). Loss of p53 was found to confer sensitivity to paclitaxel as suggested previously (Supplementary Fig. 2A) ${ }^{30}$. Interestingly, 17 compounds demonstrated selective sensitivity in p53 $158 \mathrm{G}$ cells compared with wtp53 and null cells (Fig. 2a, Supplementary Fig. 2A, B). Among these, potent inhibitory effects (10-fold differences in $\mathrm{ED}_{50}$ values) against $\mathrm{p} 53^{\mathrm{R} 158 \mathrm{G}}$ cells were confirmed in bleomycin, AZD7762, cladribine, topotecan, nocodazole, volasertib, 17-AAG, belinostat (PXD101), bosutinib, and JQ1 using dose-response evaluation (Supplementary Fig. 2C). Consistent with previous reports $9,10,31$, inhibitors of HSP90, histone deacetylase (HDAC) and polo-like kinase (PLK) demonstrated selective activity against mutp53 cells.

HDAC inhibitors have demonstrated synergistic activities through epigenetic mechanisms with a variety of clinically approved agents in several cancers. Accordingly, the clinically approved belinostat ${ }^{32}$ was selected to delineate the underlying mechanism conferring sensitivity to mutp53. We performed a combination screening on belinostat with cisplatin, a DNAdamaging cytotoxic agent that forms the backbone of chemotherapy against metastatic SCC. In this context, the cell viability (\%) and combinatorial score of a belinostat/cisplatin combination was quantified in our study models (Fig. 2b, c). The combination was antagonistic on $\mathrm{p} 53^{\mathrm{wt}}$ cells (Bliss value $>0$ ), possibly due to concurrent activation of cell cycle checkpoints ${ }^{33,34}$. In contrast, profound synergistic response was observed in $\mathrm{p} 53^{\mathrm{R} 158 \mathrm{G}}$ cells (Bliss value $<0)$ when combining belinostat $(0.1 \mu \mathrm{M})$ with cisplatin $(0.1-10 \mu \mathrm{M})$, indicating that the observed cell response was greater than the predicted values (Fig. 2c). Concomitantly, while belinostat lowered cisplatin $\mathrm{IC}_{50}$ in mutp53 ${ }^{\mathrm{R} 158 \mathrm{G}}$ Calu-1 cells, it had little effect on cell-lines with wild-type or null p53 status (Fig. 2d). The enhanced cytotoxicity was validated in $\mathrm{H} 2170$ cells, with belinostat augmenting cisplatin-induced caspase 3 and PARP cleavage (Fig. 3a). The fold increase of cleaved PARP and caspase 3 were compared across cisplatin treatment and cisplatin/belinostat combination to indicate presence of synergy (Fig. 3b). Interestingly, similar observation was observed in other cancer types harboring Arg ${ }^{158}$ p53 mutations, including $\mathrm{H} 441$ (lung adenocarcinoma, p53 ${ }^{\mathrm{R} 158 \mathrm{~L}}$ ), H661 (lung large cell carcinoma, p53 ${ }^{\mathrm{R} 158 \mathrm{~L}}$ ), and H747 (colorectal carcinoma, p53 ${ }^{\mathrm{R} 158 \mathrm{~L}}$ ) (Fig. 3a, b). On the contrary, cancer cells expressing other hotspot GOF p53 mutations, such as LUSC cells $\mathrm{H} 596$ (p53 ${ }^{\mathrm{G} 245 \mathrm{C}}$ ) and ChaGo-k-1 (p53 ${ }^{\mathrm{C} 275 \mathrm{~F}}$ ); lung adenocarcinoma H1417 (p53 ${ }^{\mathrm{R} 175 \mathrm{~L}}$ ) and H1975 (p53 $\left.{ }^{\mathrm{R} 273 \mathrm{H}}\right)$; breast carcinoma SK-BR-3 (p53 $\left.{ }^{\mathrm{R} 175 \mathrm{H}}\right)$, HCC70 (p53 $\left.{ }^{\mathrm{R} 248 \mathrm{Q}}\right), \quad$ BT-549 $\left(\mathrm{p} 53^{\mathrm{R} 249 \mathrm{~S}}\right)$ and MDA-MB-468 (p53 $\left.{ }^{\mathrm{R} 273 \mathrm{H}}\right)$; pancreatic carcinoma MIA-Paca-2 (p53 $\left.{ }^{\mathrm{R} 248 \mathrm{~W}}\right)$ and PANC-1 (p53 $\left.{ }^{\mathrm{R} 273 \mathrm{H}}\right)$; did not show increased in apoptotic markers when belinostat was combined with cisplatin (Fig. 3b, Supplementary Fig. 3A, B). 
a

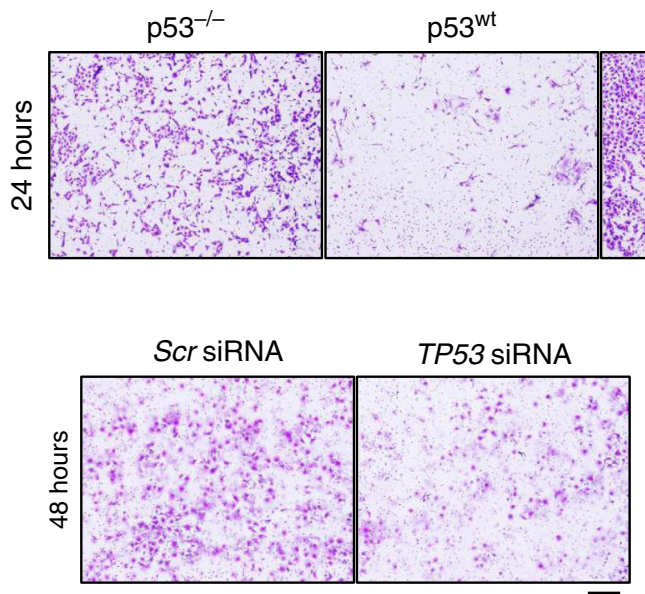

$p 53^{R 158 G(3)}$

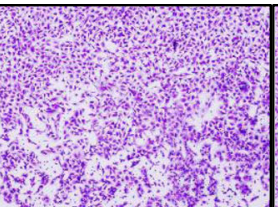

$\mathrm{p} 53^{\mathrm{R} 158 \mathrm{G}(8)}$

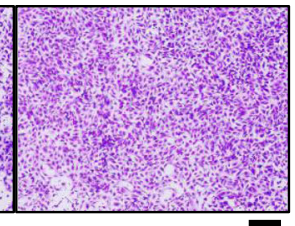

b

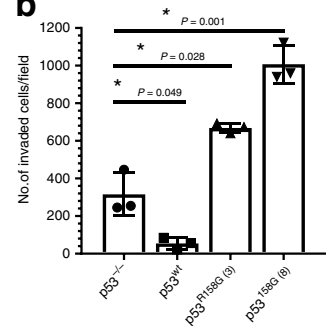

C

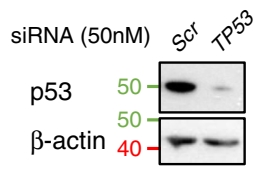

d
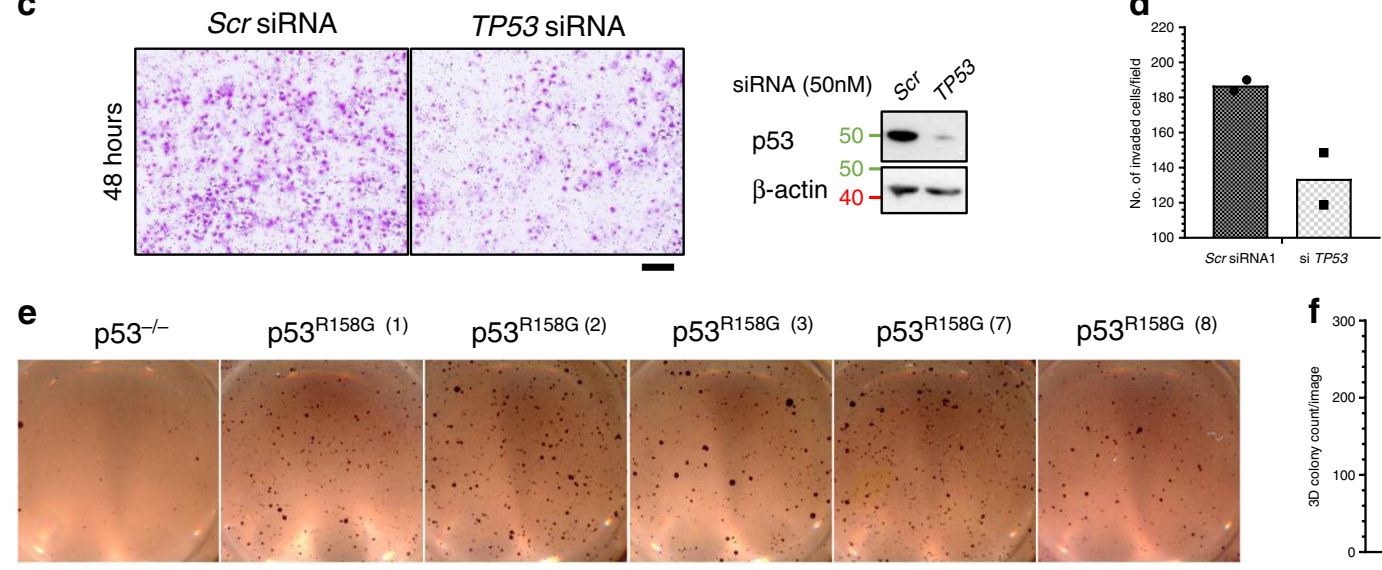

g

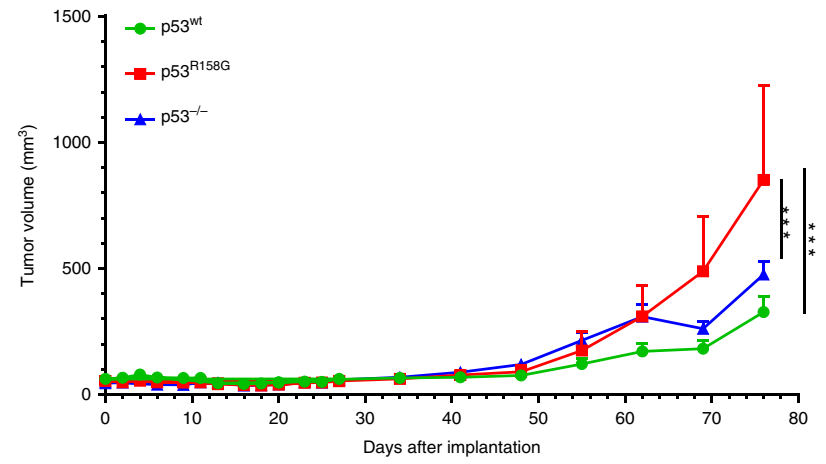

$\mathbf{h}$

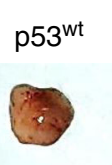

0.5381

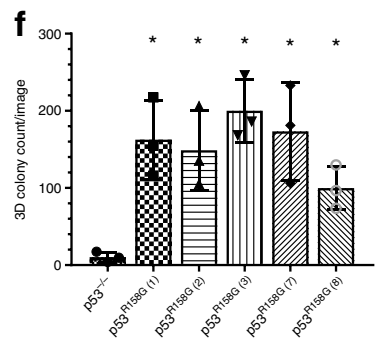

Xenograft $\mathrm{p} 53^{\mathrm{R} 158 \mathrm{G}}$

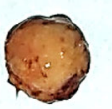

1.0658
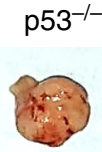

0.5932

Tumor size $\left(\mathrm{mm}^{3}\right)$

Fig. 1 Mutation at Arg ${ }^{\mathbf{1 5 8}}$ is a GOF p53 isoform. a-d Cell invasion assays were performed on isogenic Calu- 1 cells (p53-/-, p53wt and mutp53R158G) and H2170 cells. Cells seeded in Matrigel invasion chambers were fixed and stained at the indicated time point. Representative images were shown for Calu-1 clones ( $n=3$ independent experiments) (a) and H2170 cells with Scr of TP53 siRNA knockdown ( $n=2$ independent experiments) (c). Immunoblots verifying p53 knockdown are shown on the right. The number of cells in four random microscopic fields $\times 4$ were quantified for $\mathrm{Calu}-1$ (b) and $\mathrm{H} 2170$ (d) cells. Data are expressed as mean \pm SD. $50 \mathrm{nM}$ of siRNA used per transfection. Two tailed Student's $t$-test; ${ }^{\star} P<0.05$. Scale bar, $200 \mu \mathrm{m}$. e, f Anchorageindependent colony forming assays were performed on isogenic Calu- 1 cells (p53-/- and five independent mutp $53^{\mathrm{R} 158 \mathrm{G}}$ clones). Representative images of colony formation for each cell type, stained with MTT at assay endpoint (e). The number of colonies were quantified (f) and expressed as mean of triplicates \pm SD ( $n=3$ independent experiments). Two tailed Student's $t$-test; ${ }^{\star} P<0.05 . \mathbf{g}, \mathbf{h}$ In vivo growth rates of $p 53^{-/-}, p 53^{\text {wt }}, p 53^{R 158 G}$ cells were measured upon day of implantation and monitored over time (g). Images shown are representative tumor sizes at assay endpoint (h). Tumor sizes are presented as mean \pm SEM $\left(n=5\right.$ animals). Two-way ANOVA with Bonferroni correction; ${ }^{\star} P<0.05 ;{ }^{\star \star} P<0.01 ;{ }^{\star \star \star} P<0.001$.

Similar lack of synergism was observed in other lung cancer cells with p53 deletion (Calu-1), point-nonsense mutation (H520, SKMES-1) and wild-type p53 (A549) (Fig. 3b, Supplementary Fig. 3A). These findings indicate specific mechanistic underpinnings of the observed synergy in Arg ${ }^{158}$ mutp53 cells.

Acetylation of mutp53 ${ }^{\mathrm{R} 158 \mathrm{G}}$ induced pro-apoptotic phenotype. As HDAC inhibitors can acetylate histones and other cellular proteins, possible mechanisms that modulate mutp53 function include Lysine acetylation of histones affecting DNA configuration favoring mutp53 access to DNA-binding elements, or direct modification of mutp53 itself leading to alternative DNA binding. To evaluate this, we first demonstrated that a low, sub-cytotoxic concentration of belinostat $(0.1 \mu \mathrm{M})$ was sufficient to acetylate both H3 and H4 (Fig. 3c) in H2170 cells, and was synergistic with cisplatin in apoptotic assays (Fig. 3d, f-h; Supplementary Fig. 3C, D). The transcriptional regulation of p53 targets (CDKN1A, PUMA, PMAIP1, BAX) and Bcl-2 family members (BCL2, BAD, $B A K 1)$ strongly implicated p53 transcriptional regulation in this observed synergy with DNA-damaging cisplatin (Fig. 3j, k). The dependence on mutp53 $3^{\mathrm{R} 158 \mathrm{G}}$, functioning through active transcription regulation, was further substantiated by the positive p53-reporter-luciferase activity of combination drug-treatment (Supplementary Fig. 4A). In addition, DNA-binding affinity of mutp53 was validated with gel retardation assay, with wtp53 and mutp53 showing comparable binding affinity to a 31-bp p53 response element sequence from CDKN1A (Supplementary Fig. 4B, C). Consistently, depletion of p53 from $\mathrm{H} 2170$ parental cells with different short hairpin (shRNA) constructs or small interfering RNA (siRNA) reduced PARP and caspase 3 cleavage 
a

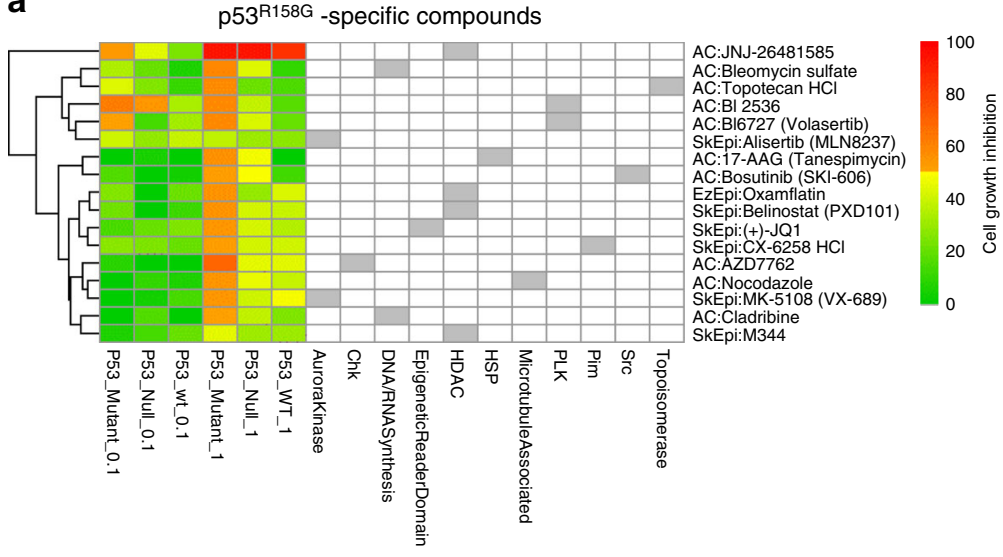

d

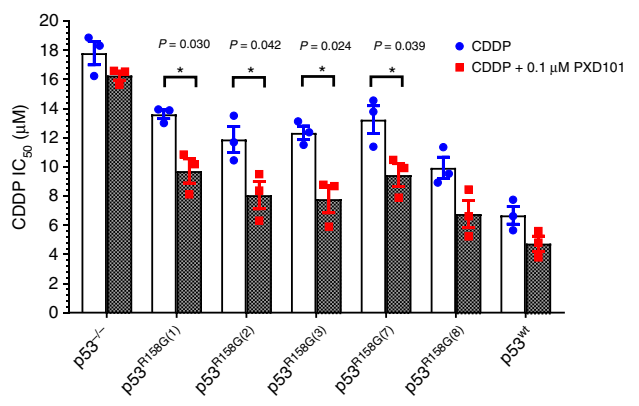

b

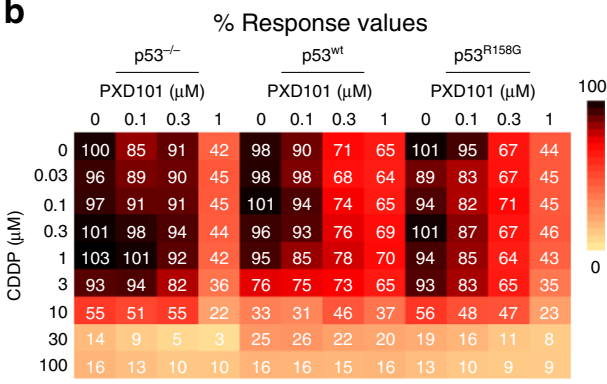

C

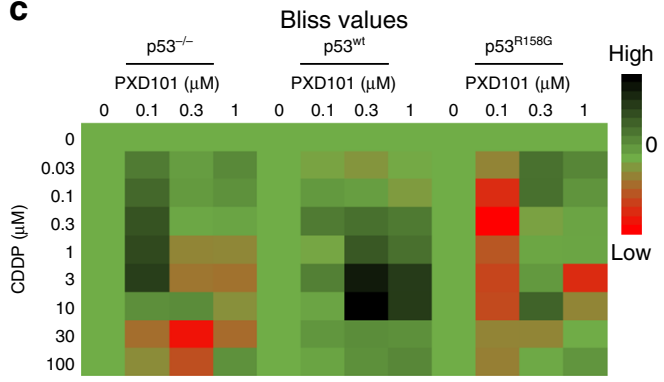

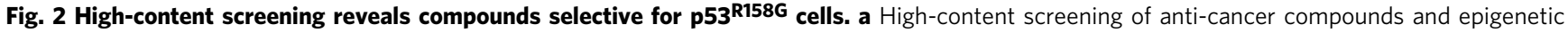
modulators on $\mathrm{p} 53$ clones. The efficacy of the tested compounds was quantified relative to the mean viability of vehicle-treated cells (384-well format, in triplicates) $72 \mathrm{~h}$ post-treatment $(n=1)$. Heatmap shows compounds filtered for specificity to $\mathrm{p} 53^{\mathrm{R} 158 \mathrm{G}}$ cells (growth inhibition $>50 \%$ in $\mathrm{p} 53^{\mathrm{R} 158 \mathrm{G}}$; $<50 \%$ in p53-/-, p53wt). b, c Response profile for belinostat (PXD101) and cisplatin (CDDP). Percent response values represent normalized growth relative to vehicle control (b). Data are presented as mean cell viability ( $n=3$ independent experiments). Viability response of belinostat/cisplatin combination from b was evaluated using the Bliss combination model (c). Bliss Scores are shown, with lower scores (synergy) highlighted in increasingly sharper shades of red. High Bliss values $(\mathrm{Cl}>0)$ indicate antagonism; low values $(\mathrm{Cl}<0)$ indicate synergy $\left(n=3\right.$ independent experiments). $\mathbf{d}$ Cisplatin $I C_{50}$, with or without belinostat $(0.1 \mu \mathrm{M})$, was tabulated for Calu- 1 isogenic cells (p53-/-, p53wt, p53R158G). Cell viability was measured with MTS assay $72 \mathrm{~h}$ post-treatment. Data are represented as mean $I C_{50} \pm S D$ ( $n=3$ independent experiments). Two tailed Student's $t$-test; ${ }^{\star} p<0.05$.

(Supplementary Fig. 4D). Apoptosis induced by the combination treatment was significantly abrogated in the shp53 cells (Supplementary Fig. 4E). Logically, destabilization and depletion of GOF mutp53 explains potent anti-tumor cytotoxicity 9,10 , but paradoxically, we observed no reduction of mutp53 $2158 \mathrm{G}$ in $\mathrm{H} 2170$ cells despite robust apoptosis (Fig. 3e). Rather, analyses of the post-translational modifications (PTM) of p53 showed that while cisplatin dose-dependently increased p53 phosphorylation and acetylation, combination with belinostat potentiated only its acetylation (Fig. 3e).

To establish the role of $\mathrm{p} 53^{\mathrm{R} 158 \mathrm{G}}$ in promoting apoptosis, we conducted synonymous experiments using isogenic Calu-1 celllines. Cisplatin alone and in combination with belinostat triggered comparable S-phase arrest regardless of the p53 status, suggesting that the synergy is independent of its cytostatic effect (Figs. 3i, 4c). Cisplatin alone induced pronounced apoptotic response in both p53 $3^{\mathrm{wt}}$ and $\mathrm{p} 53^{\mathrm{R} 158 \mathrm{G}}$ cells, however, enhanced cytotoxicity and $\mathrm{p} 53$ acetylation by belinostat were restricted to p53R158G cells (Fig. 4a, b, d), which is concordant with the $\mathrm{IC}_{50}$ values (Fig. 2d). Transcriptional activation of MDM2 was only observed in wtp53 but not mutp53 or null cells (Fig. 4e); whereas, $C D K N 1 A, P U M A$, and $B A X$ were induced post-treatment in mutp53 but not null cells (Fig. $4 \mathrm{f}-\mathrm{i}$ ), implicating $\mathrm{p} 53^{\mathrm{R} 158 \mathrm{G}}$ in the synergistic pro-apoptotic effect.

To investigate the role of $\mathrm{p} 53$ acetylation in mediating the proapoptotic function of mutp53, we first constructed $\mathrm{p} 53^{\mathrm{R} 158 \mathrm{G}}$ mutants by substituting the Lysine residues at the DBD (p53 ${ }^{\mathrm{R} 158 \mathrm{G}(\mathrm{DBD}, \mathrm{K}-\mathrm{A})}$ ), C-terminal domain (p53 ${ }^{\mathrm{R} 158 \mathrm{G}(\mathrm{CT}, \mathrm{K}-\mathrm{A})}$ ) or the whole protein $\left(\mathrm{p} 53^{\mathrm{R} 158 \mathrm{G}(\mathrm{K} 20 \mathrm{~A})}\right)$. Expectedly, these modifications were unable to overcome cell death induced by single agent cisplatin, which could occur via the p53-independent extrinsic apoptotic pathway ${ }^{35}$. Nonetheless, belinostat-induced synergy was abrogated in $\mathrm{p} 53^{\mathrm{R} 158 \mathrm{G}(\mathrm{DBD}, \mathrm{K}-\mathrm{A})}$ and $\mathrm{p} 53^{\mathrm{R} 158 \mathrm{G}(\mathrm{K} 20 \mathrm{~A})}$ cells (Fig. $4 \mathrm{a}$, b, d), both cell types with impaired Lysine acetylation at the p53 DBD. In contrast, the synergistic effect was maintained in $\mathrm{p} 53^{\mathrm{R} 158 \mathrm{G}}$ (CT,K-A) clones (Fig. 4b), suggesting that C-terminal acetylation is not involved in mutp53-effected cytotoxicity.

To compare the impact of acetylation and phosphorylation on p53 ${ }^{\mathrm{R} 158 \mathrm{G}_{-} \text {-dependent apoptosis, we conducted high-content }}$ immunofluorescence imaging to detail the post-translational events in individual nuclei (Fig. 4j), and two key observations were made. Firstly, single treatment of belinostat and cisplatin increased the acetylated-p53 population (Q4), with the combination treatment further augmented cells in Q4 (Supplementary Fig. 5A, C). Secondly, cisplatin but not belinostat treatment strongly increased the phosphorylated-p53-labelled cell population (Q3), and combination treatment had no effect on cells in Q3 (Supplementary Fig. 5B, D). This data demonstrated the positive correlation of acetylated $\mathrm{p} 53^{\mathrm{R} 158 \mathrm{G}}$ with combination treatment, which significantly triggered cellular apoptosis. To further validate the importance of $\mathrm{p} 53^{\mathrm{R} 158 \mathrm{G}}$ acetylation, isogenic $\mathrm{p} 53$ cell-lines were treated with tenovin-6, a potent sirtuin inhibitor and known acetylator of $\mathrm{p} 53^{36}$. While p53-expressing cells were more sensitive to tenovin-6 (Fig. 4k), acetylation of $\mathrm{p} 53^{\mathrm{R} 158 \mathrm{G}}$ increased cleavage 
a

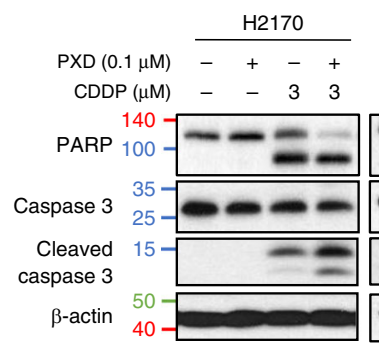

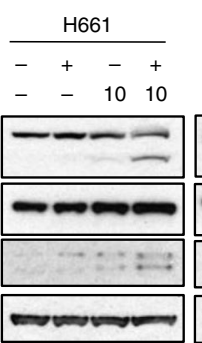

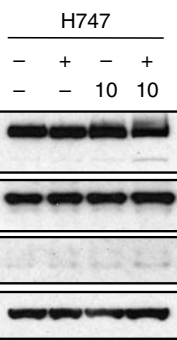

b

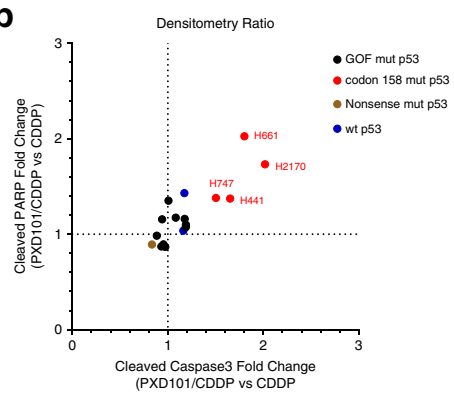

C

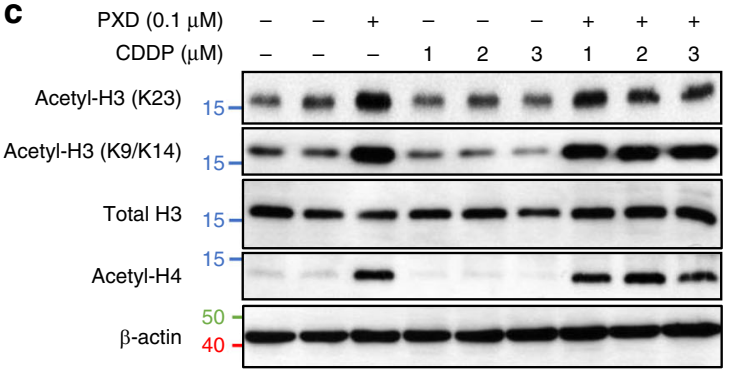

d

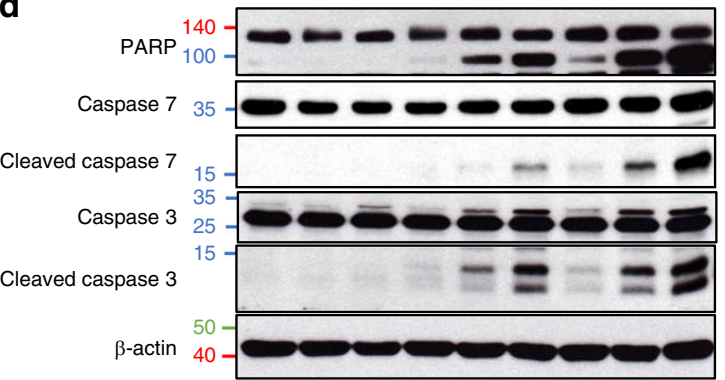

e

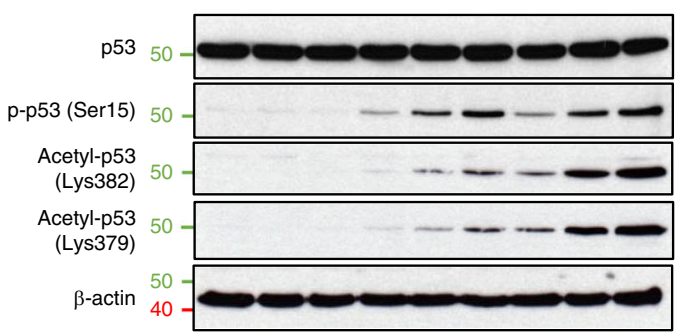

f

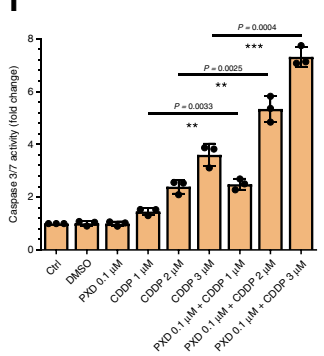

g

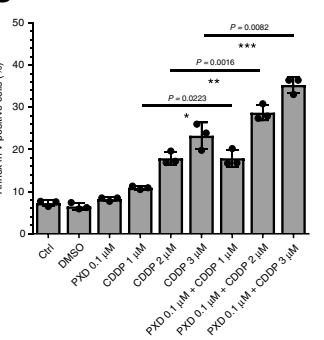

i

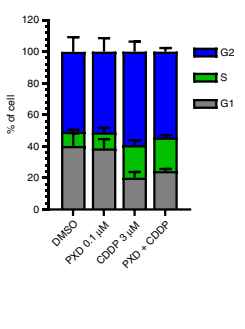

h

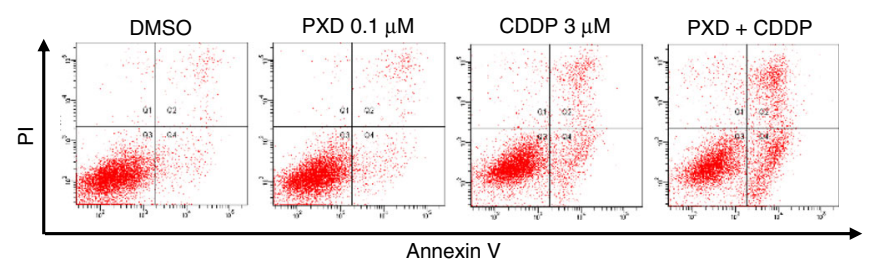

j

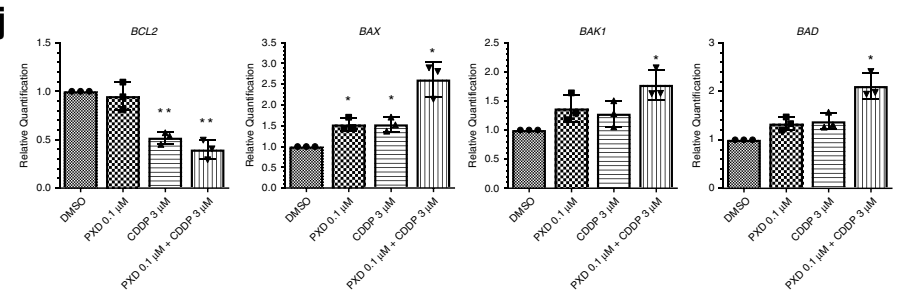

k

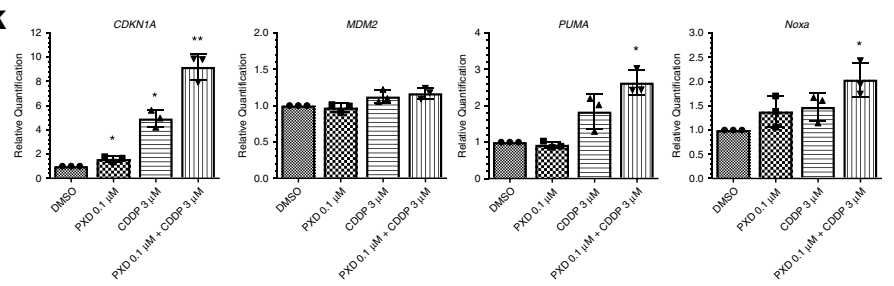

Fig. 3 Synergistic cytotoxicity of cisplatin and belinostat in carcinoma cells with $\mathbf{A r g}^{\mathbf{1 5 8}}$ mutp53 status. a Western blot measuring the changes in PARP and caspase-3 in Arg ${ }^{158}$ mutp53 cells (H2170, H441, H661, and H747) after 48 h treatment with belinostat (PXD101; 0.1 $\mu$ M) and cisplatin (CDDP; 3 or $10 \mu \mathrm{M})$. $\beta$-actin shown as loading control ( $n=3$ independent experiments). b Densitometry of cleaved PARP ( $x$-axis) and caspase 3 ( $y$-axis), respectively, for blots in Fig. 3a and Supplementary Fig. 3A, B. Data was quantified and normalized to $\beta$-actin, tabulated as ratio of belinostat/cisplatin combination to cisplatin alone (b). Data are represented as mean of three independent experiments. c-e H2170 cells were treated with increasing concentrations of cisplatin $(1,2,3 \mu \mathrm{M})$ in combination with belinostat $(0.1 \mu \mathrm{M})$ for $48 \mathrm{~h}$. Western blot indicating the changes in endogenous histones (c), apoptotic markers (d), and post-translational modifications of p53 (e). $\beta$-actin shown as loading control ( $n=3$ independent experiments). $\mathbf{f}-\mathbf{i}$ Effects of the indicated treatments on caspase $3 / 7$ activation (f), apoptosis (Annexin $\vee$ staining) $(\mathbf{g}$, $\mathbf{h}$ ) and cell cycle (PI staining) (i) were quantified after $48 \mathrm{~h}$. Data are represented as mean $\pm \mathrm{SD}\left(n=3\right.$ independent experiments). Two tailed Student's $t$-test; ${ }^{\star} P<0.05,{ }^{\star \star} P<0.01,{ }^{\star \star \star} P<0.001$. $\mathbf{j}-\mathbf{k} \mathrm{RT}$-qPCR analyses of the changes in mRNA levels of apoptotic markers (BCL2, BAX, BAK1, BAD) (j) and p53 downstream targets (CDKN1A, MDM2, PUMA, PMAIP1) (k) in H2170 cells $48 \mathrm{~h}$ post-treatment. Data are represented as mean \pm SD ( $n=3$ independent experiments). Two tailed Student's $t$-test; ${ }^{\star} P<0.05,{ }^{\star \star} P<0.01$.

of PARP and caspase 3 (Fig. 4l). Collectively, acetylation of the $\mathrm{DBD}$ is crucial to effecting apoptosis by mutp53 $158 \mathrm{G}$.

Mutp53 ${ }^{\mathrm{R} 158 \mathrm{G}}$ binds to distinct $\mathrm{DNA}$ sequence motifs. We postulated that mutp $53^{\mathrm{R} 158 \mathrm{G}}$ binds to and activates a distinct spectrum of chromatin regulatory genes from wtp53, which may be significantly altered by drug-induced acetylation. Firstly, stateof-the-art molecular modelling and simulation studies were performed to compare the structural dynamics of wild-type p53, mutp $53^{\mathrm{R} 158 \mathrm{G}}$ and acetylated-mutp $53^{\mathrm{R} 158 \mathrm{G}}$ using monomers of the respective DBD. The loss of the $\mathrm{R} 158$ sidechain creates a large 
a
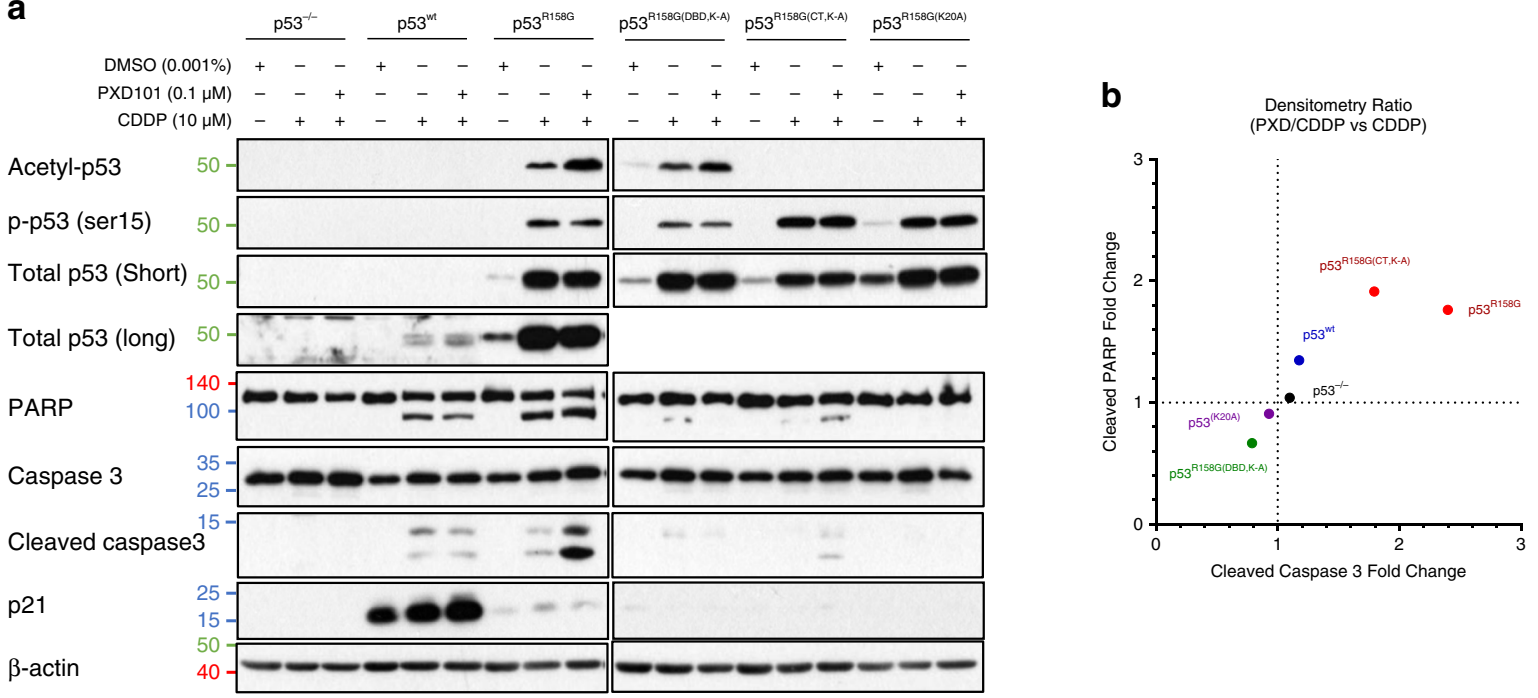

C

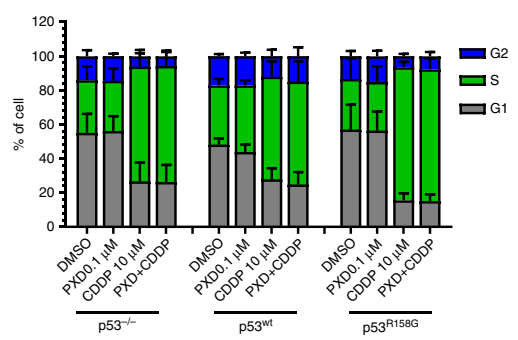

d

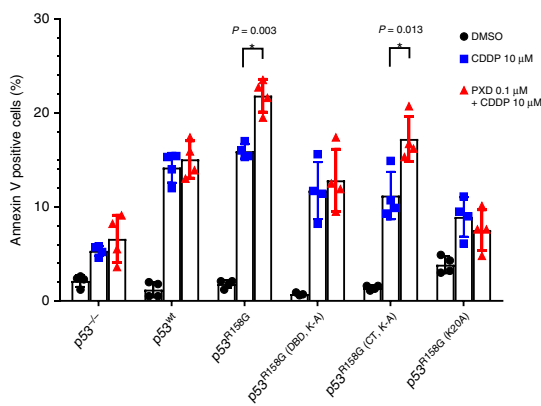

j

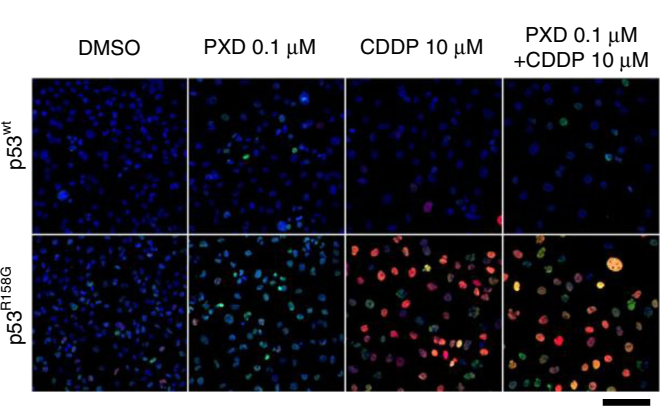

e

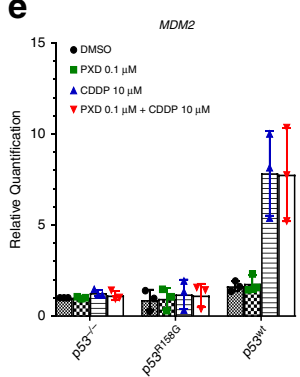

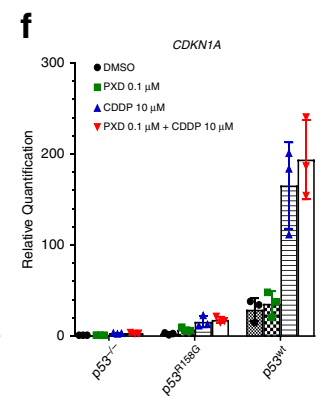

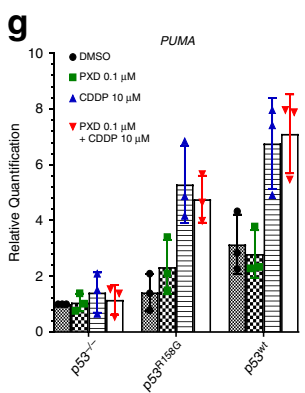

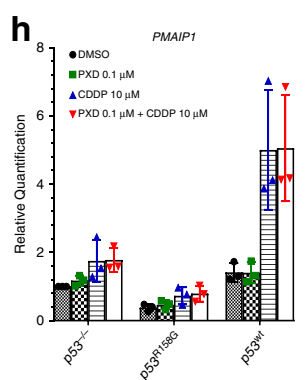

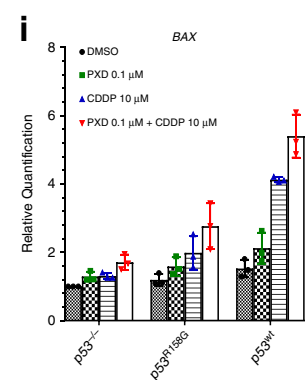

$\mathbf{k}$

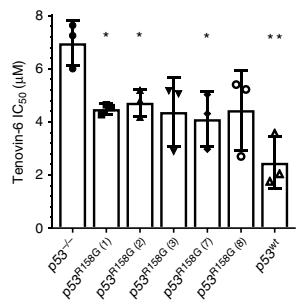

cavity that changes the structure of the DBD - most notable is the loss of the stability of helix $\mathrm{H} 1$, which is responsible for dimer formation of activated p53 (Supplementary Fig. 6A, C) -that could likely disrupt key interactions between the DBD (K120, R280, R248) and DNA. Interestingly, acetylation of the Lysine residues within the $\mathrm{DBD}$ reduces the sidechain positive charges, resulting in structural and chemical alterations, which suggest restoration of the dimerization capacity of the core domain of mutp53 ${ }^{\mathrm{R} 158 \mathrm{G}}$ (Supplementary Fig. 6B, D). While the key interactions of K120 with the major groove of the DNA remain 
Fig. 4 Acetylation of mutp53 at the DBD is required for the induction of p53-dependent apoptosis. $\mathbf{a}$, $\mathbf{b}$ Western blot measuring the changes in the indicated protein after $48 \mathrm{~h}$ treatment with belinostat (PXD101; $0.1 \mu \mathrm{M})$ and cisplatin (CDDP; $10 \mu \mathrm{M})$ in Calu-1 isogenic cells generated through sitedirected mutagenesis (p53-/-, p53wt, p53R158G, p53R158G(DBD, K-A), p53R158G(CT, K-A), p53R158G(K20A)) ( $n=3$ independent experiments) (a). $\beta$-actin shown as loading control. Densitometry of cleaved PARP ( $x$-axis) and caspase 3 ( $y$-axis) was quantified and normalized to $\beta$-actin, tabulated as ratio of belinostat/cisplatin combination to cisplatin alone (b). Data are represented as mean of three independent experiments. c, $\mathbf{d}$ Cell cycle analysis (PI staining) (c) and apoptotic profile (Annexin $\vee$ staining) (d) were evaluated 48 hours post-treatment. Data are represented as mean IC $50 \pm S D(n=4$ independent experiments). Two tailed Student's t-test; ${ }^{\star} P<0.05$. e-i RT-qPCR analyses of the changes in mRNA levels of MDM2 (e), CDKN1A (f), $P U M A$ (g), PMAIP1 (Noxa) (h), BAX (I) in p53-/-, p53 $3^{\mathrm{wt}}, \mathrm{p} 53^{\mathrm{R} 158 \mathrm{G}}$ cells $48 \mathrm{~h}$ post-treatment. Data are represented as mean $\pm \mathrm{SD}$ ( $n=3$ independent experiments). $\mathbf{j}$ Immunofluorescence staining was performed to determine the colocalization of acetyl-p53 (Lys382) (Alexa Fluor-488) and p-p53 (Ser15) (Alexa Fluor-568) in p53wt and p53R158G cells. Eight independent fields were taken for each condition with a minimum of 50 nuclei per field. Representative confocal images shown at $\times 40$ magnification ( $n=3$ independent experiments). Merged images displayed with blue indicates DAPI, green indicates acetylp53, red indicates p-p53, whereas yellow indicates colocalization of p- and acetyl-p53. Scale bar, $50 \mu \mathrm{m}$. $\mathbf{k}$ Tenovin- $6 \mathrm{IC}_{50}$ was quantified in Calu-1 isogenic clones $72 \mathrm{~h}$ post-treatment. Data are represented as mean IC ${ }_{50} \pm \mathrm{SD}\left(n=3\right.$ independent experiments). Two tailed Student's $t$-test; ${ }^{\star} P<0.05$; ${ }^{\star \star} P<0.01$. I Western blot indicating changes in the indicated proteins in $\mathrm{p} 53^{-/-}, \mathrm{p} 53^{\mathrm{wt}}, \mathrm{p} 53^{\mathrm{R} 158 \mathrm{G}}$ cells $48 \mathrm{~h}$ after vehicle or tenovin- 6 treatment $(3$ or $10 \mu \mathrm{M}) . \beta$-actin shown as loading control ( $n=3$ independent experiments).

impaired in the acetylated R158G mutant, it is compensated for by the interactions between acetylated K201 and the minor groove (Supplementary Fig. 6D). The most intriguing alteration in the acetylated R158G mutant is an increase in the length of the dimerization helix H1 from R181 to D186-about 1.5 extra turns of a helix - that will promote the formation of a dimer that is more stable than the WT and is also associated with the introduction of two salt bridges across the dimer interface (E180 of each monomer forms a salt bridge with R181 of the second monomer; Supplementary Fig. 6D). We speculate that this may increase DNA binding and result in the enhanced transcription activity seen in the acetylated mutp53 $3^{\mathrm{R} 158 \mathrm{G}}$. The simulations also highlighted the formation of key stabilizing interactions between the polar groups introduced by the acetylated K101 and K164 that stabilize the overall conformation of the mutp53. This supports our earlier observations that conversions of these two Lysines to Alanines in the DBD (p53 ${ }^{\mathrm{R} 158 \mathrm{G}(\mathrm{DBD}, \mathrm{K}-\mathrm{A})}$ ) resulted in attenuation of the proapoptotic activity seen in acetylated R158G (Fig. 4a, b, d).

Next, we compared the DNA-binding sequences and transcriptional targets of vehicle- and drug-treated $\mathrm{p} 53^{\mathrm{wt}}$ and p53 ${ }^{\mathrm{R} 158 \mathrm{G}}$ cells through $\mathrm{p} 53$ chromatin immunoprecipitation (ChIP) followed by sequencing (ChIP-Seq). In untreated cells, both wtp53 and mutp53 bound significantly to the proximal regions (within $1 \mathrm{~kb}$ ) of the transcription start sites (TSS) (Fig. 5a, Supplementary Fig. 7A). Drug treatment led to marked increase in genomic binding in both $\mathrm{p} 53^{\mathrm{R} 158 \mathrm{G}}$ and $\mathrm{p} 53^{\mathrm{wt}}$ cells, with higher signal intensity around the TSS-proximal regions (Fig. 5a, Supplementary Fig. 7A), suggestive of DNA-binding capability of both p53 isoforms. Importantly, predicted motif analysis for TSS-proximal peaks suggested that p53 consensus motifs were enriched not just in $\mathrm{p} 53^{\mathrm{wt}}$ but also in $\mathrm{p} 53^{\mathrm{R} 158 \mathrm{G}}$ (motif similarity $P=0.029$ and 0.039 , TOMTOM match statistic; $P=1 \times 10^{-16}$ and $1 \times 10^{-265}$, HOMER statistic) (Fig. 5a, Supplementary Fig. 7A). However, by comparing the binding patterns of wtp53 and mutp53 to TSS, we found that the mutp53 ${ }^{\mathrm{R} 158 \mathrm{G}}$ peaks were highly dissimilar from the peaks of wtp53 (Supplementary Fig. 8, column 1 row 3 ). In addition, we aligned the ChIP-seq data from the cells treated with the belinostat/cisplatin combination, and showed that TSS-proximal peaks post-treatment were distinct from the vehicle control in both wtp53 and mutp53. Interestingly, peaks enriched in drug-treated mutp $53^{\mathrm{R} 158 \mathrm{G}}$ cells resembled that of drug-treated wtp53 (Supplementary Fig. 8, column 2 row 4). These data collectively suggest that mutp $53^{\mathrm{R} 158 \mathrm{G}}$ partially retains wtp53 activity when cells are exposed to stress signal, which supports the induction of wtp53 response genes by the druginduced transactivation of $\mathrm{p} 53^{\mathrm{R} 158 \mathrm{G}}$ in $\mathrm{H} 2170$ cells (Supplementary Fig. 4A), as well as the increased DNA-binding affinity of mutp53 upon acetylation (Supplementary Fig. 4B, C).
To identify the genes activated by acetylated $\mathrm{p} 53^{\mathrm{R} 158 \mathrm{G}}$ which are associated with the induction of apoptosis, we compared the treatment-induced perturbations of transcriptomic profiles (by Ampliseq RNA sequencing) between wild-type and mutant cells. These gene panels were subjected to KEGG ontogeny enrichment analysis. Expectedly, genes mediating p53 signaling were elevated in p53 cells after treatment $\left(P\right.$-value $\left.=7.87 \times 10^{-11}\right)$; in p53 ${ }^{\mathrm{R} 158 \mathrm{G}}$, genes associated with cell cycle, DNA replication and DNA damage repair pathways were prioritized (Supplementary Fig. 7B). We further analyzed gene sets obtained from both ChIPseq and AmpliSeq for concordance of significantly perturbed genes pre- and post-treatment $\left(\log _{2}>1.5\right)$, also found to be bound by $\mathrm{p} 53$ within the proximal regions $(<10 \mathrm{~kb}$ from TSS), as direct p53 targets (Fig. 5b, Supplementary Table 4). Selected genes were validated with $\mathrm{qPCR}$, and consistently, direct $\mathrm{p} 53^{\mathrm{wt}}$ binding increased expression of canonical p53 downstream genes (MDM2, GADD45A, PMAIP1) (Supplementary Fig. 7C-E, I-K). Among the mutp53-bound target genes, TRAIP and RAD51 were markedly induced ( $\log _{2}$-fold $=2.72$ and 2.767 , respectively) after drug treatment relative to wild-type cells (Supplementary Table 4, Fig. 5c, d, Supplementary Fig. 7F, L). Work on other p53 hotspot mutants have described part of the mechanistic basis for mutp53's GOF as direct interaction with E26 transformation-specific (ETS) motifs ${ }^{37}$. Two chromatin regulatory genes downstream of ETS2, $K M T 2 D$, and $K A T 6 A^{22}$, reported to be positively associated with hotspot GOF mutp53 (R175H, R248Q, R248W, R249S, or $\mathrm{R} 273 \mathrm{H})$, were neither transactivated nor upregulated in $\mathrm{p} 53^{\mathrm{R} 158 \mathrm{G}}$ (Fig. 5f, g, Supplementary Fig. 7G, H), thereby distinguishing DNA binding by Arg $^{158}$ mutants from other mutated p53 GOF isoforms.

RAD51 and TRAIP are key components of the DNA damage and repair mechanisms ${ }^{38-40}$. However, combination-treated p53 ${ }^{\mathrm{R} 158 \mathrm{G}}$ cells did not demonstrate increased DNA damage response when compared to p53 loss or wtp53 cells, based on the analysis of induced- $\gamma \mathrm{H} 2 \mathrm{AX}$ (Fig. 5h), a surrogate marker for DNA damage, and the quantification of broken DNA measured using comet tail length (Supplementary Fig. 9A, B). Therefore, it is unlikely that the enhanced cytotoxicity in $\mathrm{p} 53^{\mathrm{R} 158 \mathrm{G}}$ is due to altered DNA damage signaling. We postulated that NFkB pathway regulation by TRAIP, a RING domain-containing E3 ubiquitin ligase ${ }^{41}$, may explain the altered mutp53 function, as TRAIP is known to suppress $\mathrm{NFkB}^{42-45}$. We showed that TRAIP upregulation in $\mathrm{p}^{\mathrm{R}} \mathrm{R}^{\mathrm{R}} \mathrm{8} \mathrm{G}$ cells correlated with the $\mathrm{IkB}$ dephosphorylation and stabilization (Fig. 5h). Active IkB inhibits NFkB through blocking the nuclear import of p65 $5^{46}$. Accordingly, we hypothesize that acetylation of $\mathrm{p} 53^{\mathrm{R} 158 \mathrm{G}}$ may impede $\mathrm{p} 65$ activation through perturbation of the TRAIP-IkB-NFkB axis. However, we noted in the qPCR and immunoblotting analyses 
a
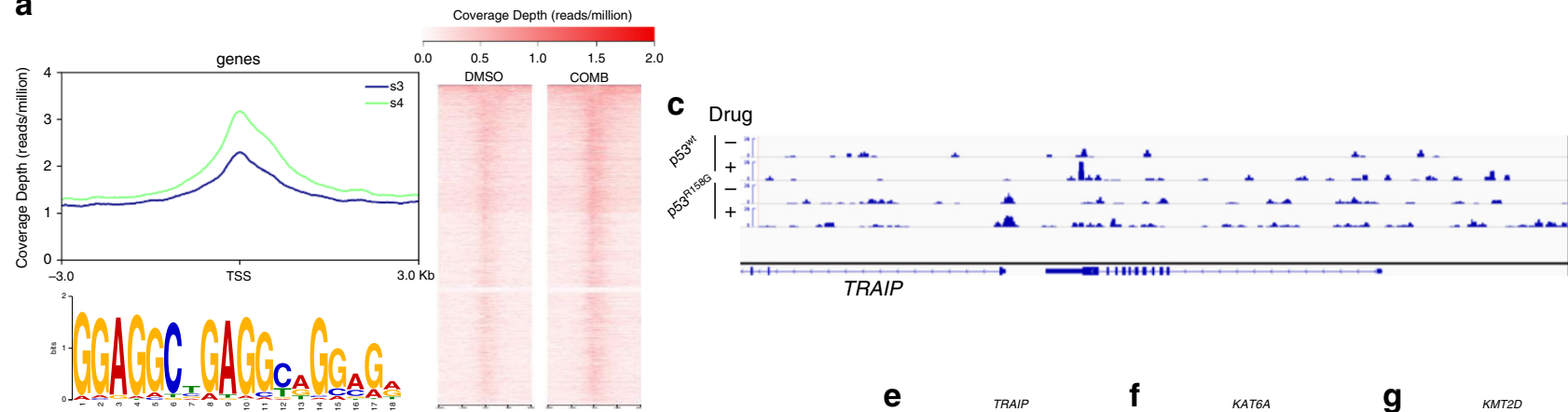

b
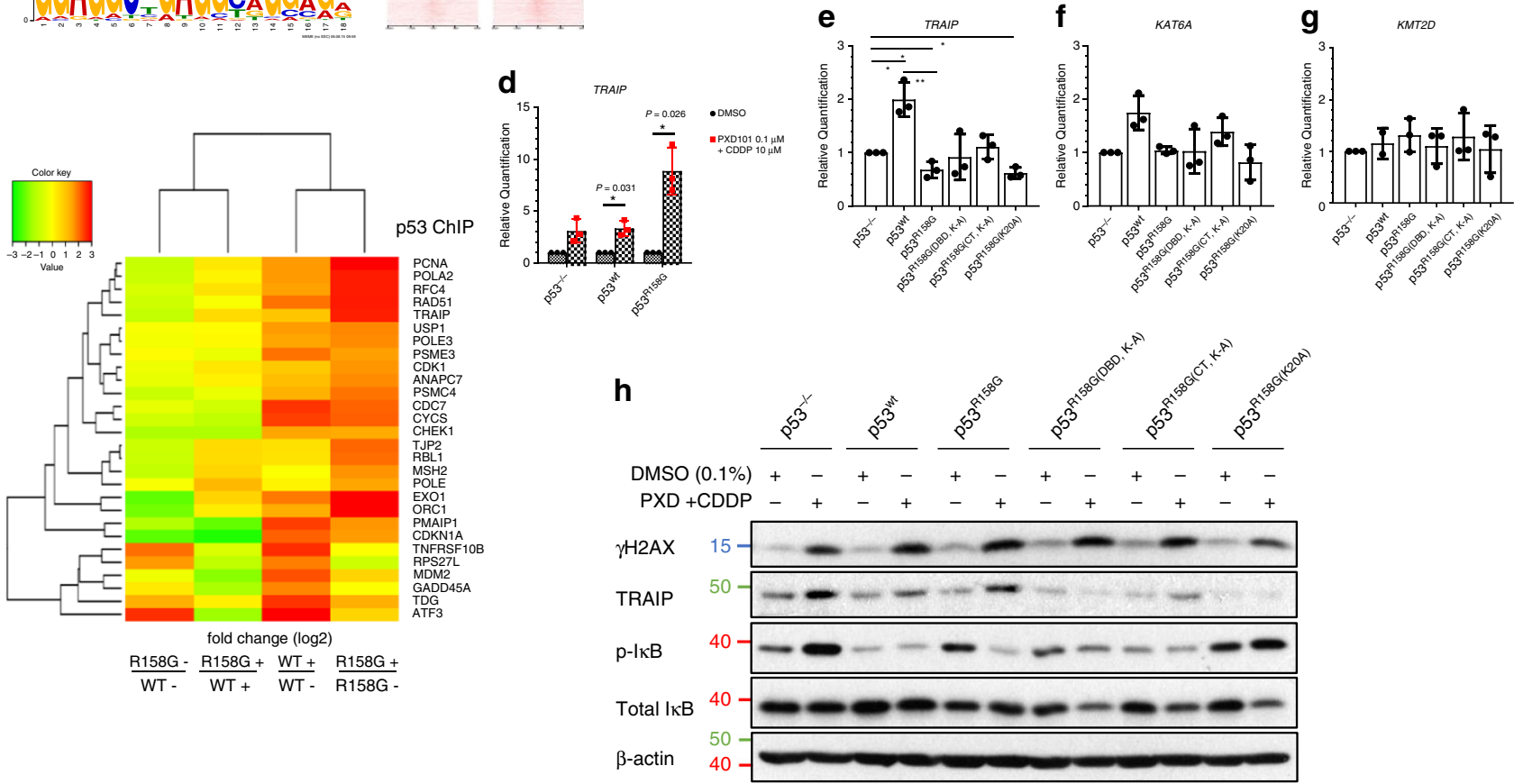

Fig. 5 Genome-wide binding and downstream transactivation of GOF p53R158G. a mutp53R158G-binding loci identified by p53 ChIP-seq analysis on Calucells treated with vehicle or belinostat/cisplatin combination for $24 \mathrm{~h}(n=1)$. Meta-peak analysis showing distribution of p53R158G-binding sites across $3000 \mathrm{bp}$ from the TSS of the nearest downstream gene (left, top). Density heatmap of the mutp53-binding sites ( \pm 3000 bp from TSS) examined by ChIPseq (Right). Canonical wild-type p53 consensus motif was identified by MEME/TomTom from the TSS-proximal ChIP-Seq peaks (bottom left).

b Comparisons of the transcriptomic levels of differentially-expressed genes (AmpliSeq analysis) bound by p53 (ChIP-seq analysis) under vehicle ( - ) or drug-treatment $(+)$ conditions. Colors from green to red indicate increasing RNA level (fold change as indicated) in each pair. Individual fold change values were tabulated in Supplementary Table 4. c Integrative Genomics Viewer display of mutp53 occupancy over promoter region of TRAIP gene in vehicle- or drug-treated cells ( $553^{w t}, p 53^{R 158 G}$ ). d RT-qPCR quantification of TRAIP gene in Calu-1 (p53-/-, p53wt, p53R158G) cells $48 \mathrm{~h}$ after vehicle or drug treatment. e-g RT-qPCR analyses of the basal mRNA levels of TRAIP (e), KAT6A (f) and KMT2D (g) in various p53 clones, compared to $p 53^{-/-}$. Data are represented as average relative quantification $\pm \mathrm{SD}\left(n=3\right.$ independent experiments). Two tailed Student's $t$-test; ${ }^{\star} P<0.05$; ${ }^{\star \star} P<0.01$. h Immunoblotting was performed to evaluate the effects of belinostat/cisplatin on the indicated targets in various p53 clones. $\beta$-actin shown as loading control ( $n=3$ independent experiments).

that TRAIP was elevated to a certain extent in $\mathrm{p} 53^{\mathrm{wt}}$ and $\mathrm{p} 53^{-1-}$ (Fig. 5d, h). As TRAIP is involved in cellular response to genotoxic lesions such as replication-associated DNA damage ${ }^{39}$, we reasoned that TRAIP is induced as part of a p53-independent physiological response to cisplatin-induced DNA cross-linking, particularly in p53 null cells. To confirm this, we extended our analyses on the remaining Calu-1 clones expressing $\mathrm{p} 53^{\mathrm{R} 158 \mathrm{G}}$. Belinostat/cisplatin co-treatment consistently elevate TRAIP and suppress $\mathrm{IkB}$ phosphorylation in these clones, whereas the same treatment condition did not alter $\mathrm{IkB}$ in $\mathrm{p} 53^{\mathrm{wt}}$ and $\mathrm{p} 53^{-/-}$cells (Supplementary Fig. 10A, B).

Acetylated p53 ${ }^{\mathrm{R} 158 \mathrm{G}}$ suppresses NFkB signaling through TRAIP. To prove this hypothesis, we first determined the changes in chromatin binding affinity of acetylated mutp53 in the context of TRAIP transactivation. Using ChIP-quantitative PCR (ChIP-qPCR), we validated the increased binding of $\mathrm{p} 53^{\mathrm{R} 158 \mathrm{G}}$ after belinostat/cisplatin treatment to the promoter region of the TRAIP gene (Supplementary Fig. 11A-C). In parallel experiments involving $\mathrm{p} 53^{\mathrm{wt}}$ and $\mathrm{p} 53^{\mathrm{R} 158 \mathrm{G}(\mathrm{K} 20 \mathrm{~A})}$ cells, there was no apparent enrichment in term of wtp53 binding to TRAIP, and more importantly, the ChIP-qPCR signal of mutp53 binding was attenuated in the $\mathrm{p} 53^{\mathrm{R} 158 \mathrm{G}(\mathrm{K} 20 \mathrm{~A})}$ variant, which cannot be acetylated (Supplementary Fig. 11B, C). Collectively, these findings strengthened the concept that acetylation of $\mathrm{p} 53^{\mathrm{R} 158 \mathrm{G}}$ leads to the transactivation of TRAIP (Fig. 5d).

We next sought to investigate the relevance of TRAIP transactivation on $\mathrm{NFkB}$ signaling in the context of differential p53 alterations. NFkB stimulation renders resistance to programmed cell death through nuclear translocation of its activated heterodimeric complex, DNA interaction and induction of 
a

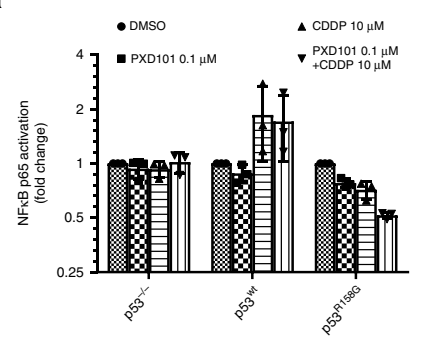

b

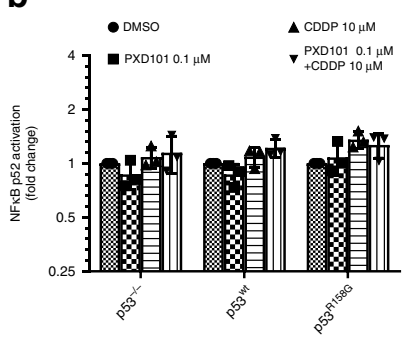

C

$\frac{\text { cytoplasmic }}{{\mathrm{p} 53^{-/-}}^{\mathrm{p} 53^{\mathrm{wt}}} \mathrm{p} 53^{\mathrm{R} 158 \mathrm{G}}}$

$\frac{\text { nuclear }}{{\mathrm{p} 53^{-/-}}^{\mathrm{p} 53^{\mathrm{wt}}} \mathrm{p} 53^{\mathrm{R} 158 \mathrm{G}}}$

$\operatorname{DMSO}(0.1 \%)+-+-+-+++-$

$\mathrm{PXD}+\mathrm{CDDP}-+-+-+\ldots+-+$

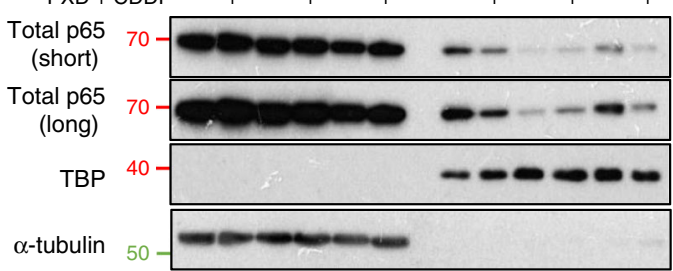

d
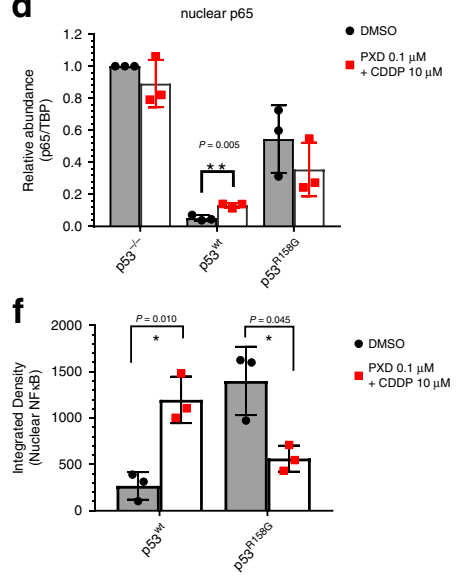

g

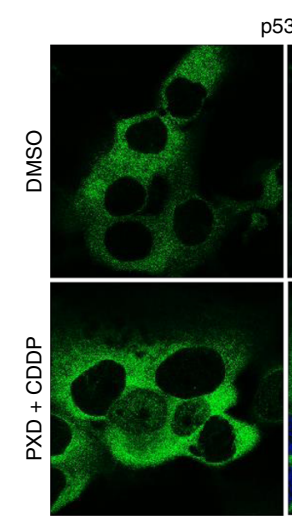

p5 $3^{\text {wt }}$

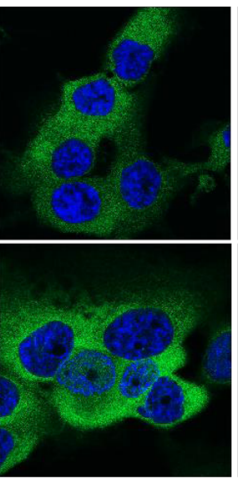

p53 ${ }^{\mathrm{R} 158 \mathrm{G}}$

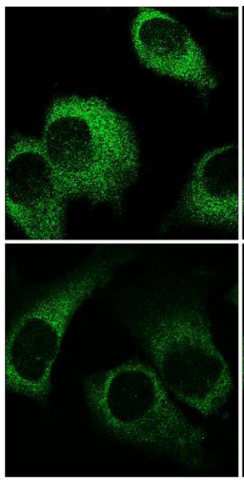

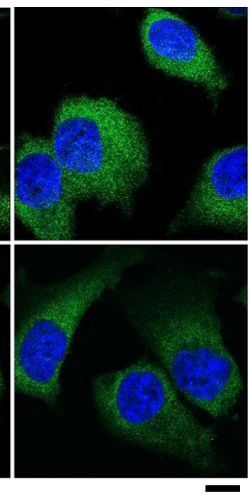

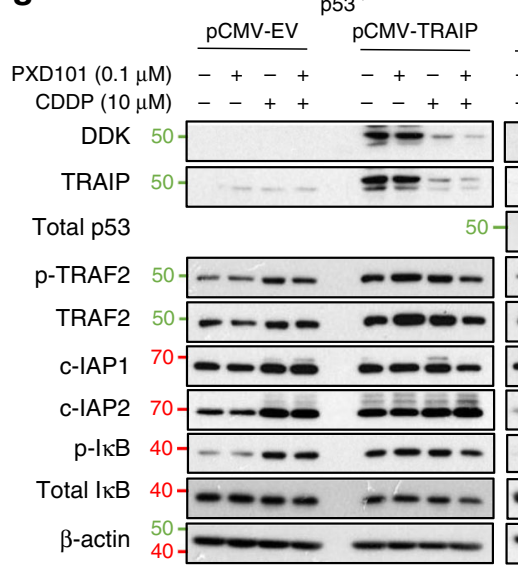

i

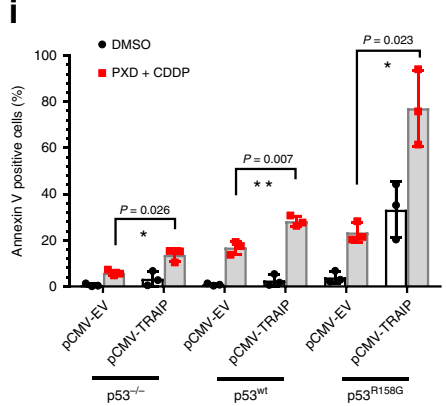

j

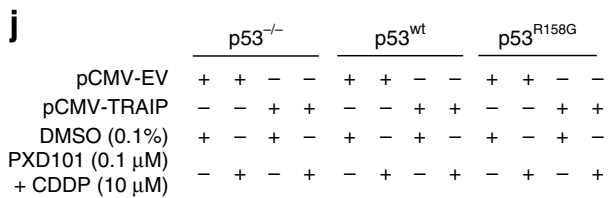

h
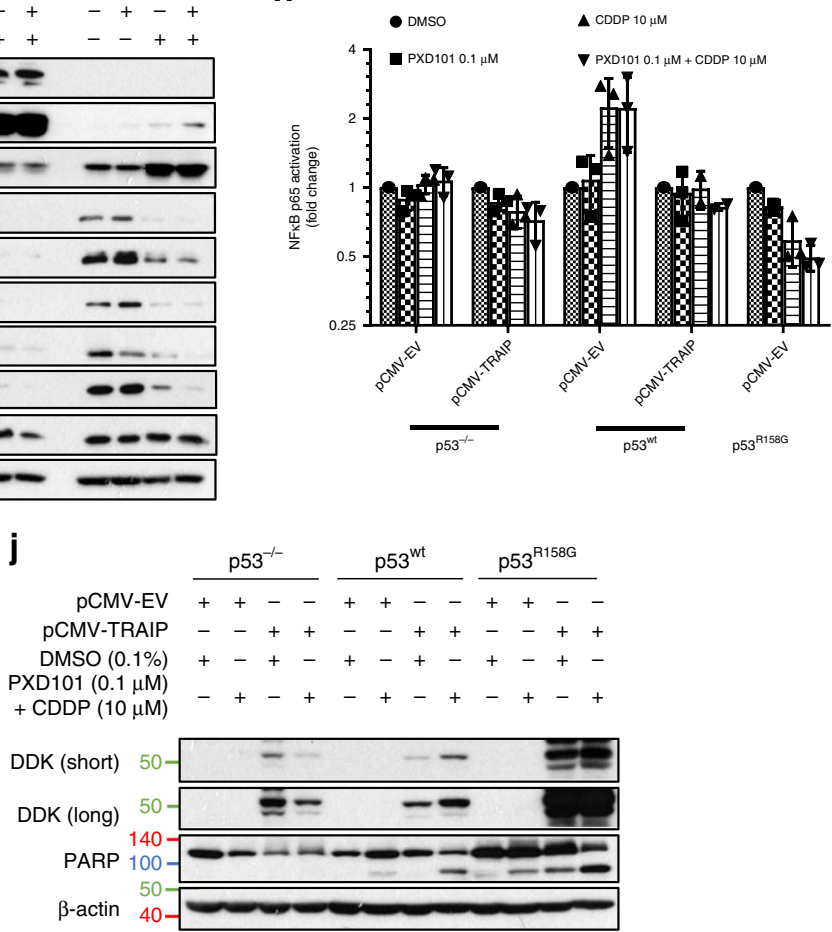

survival signals, which is regulated by an auto feedback loop involving its negative regulator $\mathrm{IkB}^{47}$. Activation of $\mathrm{NF \kappa B}$ is determined either by the canonical NFkB1/RelA complex or the non-canonical NFkB2/RelB complex. While wtp53 and NFkB are often coordinated in an opposing manner due to their contrasting cellular functions $s^{48,49}$, mutp53 proteins have been shown to promote NFkB activation ${ }^{11}$. In the context of LUSC, we first showed using DNA-binding ELISAs that cisplatin treatment increased $\mathrm{p} 65$ (RelA, NFkB p65 subunit) transactivation in p53 $3^{\mathrm{wt}}$ cells (Fig. 6a). In contrast, a reciprocal downregulation was observed in $\mathrm{p} 53^{\mathrm{R} 158 \mathrm{G}}$ cells, with a further reduction observed when combined with belinostat; whereas NFkB was unaffected in p53 deficient cells (Fig. 6a). To rule out the possible alternative involvement of non-canonical NFKB signaling, we investigated 
Fig. 6 Drug-induced TRAIP expression negatively regulates NFKB signaling in $\mathbf{p 5 3 3 ^ { \mathbf { R } 1 5 8 G }}$ cells. $\mathbf{a}$, $\mathbf{b}$ Quantification of active nuclear NFKB1 (p65) (a) and NFKB2 (p52) (b) in Calu-1 (p53-/-, p53wt, p53 R158G) cells $48 \mathrm{~h}$ after vehicle or drug treatment. Data are presented as mean \pm SD ( $n=3$ independent experiments). c, d Distribution of p65 (in cytoplasm or nucleus) was determined by Western blot (c) after nuclear-cytosolic fractionation. TATA-box binding protein (TBP) (nuclear) and $\alpha$-tubulin (cytoplasmic) were used as loading controls. Nuclear p65 expression was quantified with densitometry after normalizing to TBP $(\mathbf{d})$. Data are presented as mean \pm SD $\left(n=3\right.$ independent experiments). Two tailed Student's $t$-test; ${ }^{\star \star} P<0.01$. e, $\mathbf{f}$ Immunofluorescence staining was performed to determine the localization of p65 (Alexa Fluor-488) in p53wt and p53R158G cells $48 \mathrm{~h}$ post-treatment. At least five independent fields were taken for each condition with a minimum of 30 nuclei per group ( $n=3$ independent experiments). Representative confocal images shown at $63 \times$ magnification (e). Scale bar, $10 \mu \mathrm{m}$. Merged images displayed with blue indicates DAPI, green indicates p65. Integrated density quantifying nuclear NFKB (p65) in p53wt and p53R158G cells (f). Data are presented as mean \pm SD $(n=3$ independent experiments). Two tailed Student's $t$-test; ${ }^{\star} P<0.05$. $\mathbf{g}$ Western blot showing effects of TRAIP overexpression on the indicated proteins in Calu- 1 isogenic cells ( $p 53^{-/-}$, p53wt, p53 ${ }^{\mathrm{R} 158 \mathrm{G}}$ ) $48 \mathrm{~h}$ after vehicle or drug treatment. $\beta$-actin shown as loading control ( $n=3$ independent experiments). $\mathbf{h}$ Quantification of active nuclear NFKB1 (p65) in Calu-1 (p53-/-, p53 ${ }^{\mathrm{wt}}, \mathrm{p} 53^{\mathrm{R} 158 \mathrm{G}}$ ) cells after TRAIP overexpression with the indicated drug treatment. Data are presented as mean \pm SD $(n=3$ independent experiments). $\mathbf{i}$, j Annexin $\vee$ staining (i) and Western blotting (j) in TRAIP overexpressed cells $48 \mathrm{~h}$ post-treatment. Data are presented as mean \pm SD ( $n=3$ independent experiment). Two tailed Student's $t$-test; ${ }^{\star} P<0.05$, ${ }^{\star \star} P<0.01$.

the transactivation of $\mathrm{p} 52$ (NFkB2 subunit) and showed that DNA-binding was marginally affected in all cell types (Fig. $6 \mathrm{~b})^{50}$. Cytoplasm to nuclear shuttling of p65 is critical for the initiation of the $\mathrm{NFkB}$ pathway ${ }^{51}$. In $\mathrm{p} 53^{\mathrm{R} 158 \mathrm{G}}$ cells, drug treatment reduced nuclear accumulation of p65; conversely, pronounced p65 nuclear translocation was observed in wild-type cells, in concordance with the increase in DNA-binding assays (Fig. 6c-f). The wtp53-p65 relationship was illustrated experimentally in colon cancer cells HCT116 p53 wild-type/null pairs ${ }^{52}$, where drug combination induced $\mathrm{p} 65$ nuclear translocation in wild-type $\left(\mathrm{HCT} 116^{+/+}\right.$) but not in null (HCT116-/-) cells (Supplementary Fig. 12A-D). In addition, we observed that basal nuclear $\mathrm{NFkB}$ is kept at levels lower in p53 than in $\mathrm{p} 53^{\mathrm{R} 158 \mathrm{G}}$ or $\mathrm{p} 53$ null cells (Fig. 6c-f, Supplementary Fig. 12A, B), likely through higher TRAIP expression in wtp53 cells (Fig. 5e). Together, our findings support the contention that increased transcription of TRAIP by acetylated $\mathrm{p} 53^{\mathrm{R} 158 \mathrm{G}}$ leads to inhibition of $\mathrm{NFkB}$ through blocking $\mathrm{IkB}$ phosphorylation and nuclear import of $\mathrm{p} 65$.

To elucidate the mechanisms relating TRAIP to NFkB inhibition, we overexpressed TRAIP in both $\mathrm{p} 53^{-/-}$and $\mathrm{p} 53^{\mathrm{wt}}$ cells. Surprisingly, cisplatin alone or in combination downregulated exogenous TRAIP in $\mathrm{p} 53^{-1-}$ cells without affecting the downstream targets (Fig. 6g, left). In contrast, ectopic TRAIP expression was sustained in $\mathrm{p} 53^{\mathrm{wt}}$ cells, leading to the downregulation of TRAF2, c-IAP1, and c-IAP2, pro-survival components of the TNF receptor family ${ }^{53}$, potentially through the ubiquitin-proteasomal degradation pathway (Fig. 6g, right). These data are consistent with previous work demonstrating that TRAF2 and c-IAP are downstream effectors of TRAIP 42,45 . As previously described ${ }^{54}$, ablation of TRAF2 reduced phosphorylation and degradation of $\mathrm{IkB}$ (Fig. $6 \mathrm{~g}$, right), therefore facilitating IkB-mediated impediment of NFkB transactivation (Fig. 6h). This negative NFkB regulation by exogenous TRAIP sensitized p53expressing cells to drug-induced apoptosis, as indicated by increased Annexin $\mathrm{V}$ positive population and PARP cleavage (Fig. 6i-j). Importantly, exogenous TRAIP recapitulated $\mathrm{p} 53^{\mathrm{R} 158 \mathrm{G}}$ response to drug treatment in p53 ${ }^{\mathrm{wt}}$ cells. Consistently, acetylation of $\mathrm{p} 53^{\mathrm{R} 158 \mathrm{G}}$ is associated with p21 upregulation, p-IkB suppression and elevated TRAIP transcript in $\mathrm{H} 2170$ cells (Supplementary Fig. 13A-C). Of note, these modulations were consistent in other cell types expressing Arg ${ }^{158}$ mutp53 (H441, H661), but were not found in other GOF mutp53 cells (H1417, H1975, HCC70, MDA-MD-468, and SK-BR-3 cells) (Supplementary Fig. 13A, B), thereby highlighting the mechanistic distinctiveness of the Arg ${ }^{158}$ mutp53. Effective silencing of TRAIP markedly rescued cellular apoptosis in $\mathrm{H} 2170$ cells, as demonstrated by the reduced PARP and caspase 3 cleavage, by sustaining $\mathrm{p}-\mathrm{IkB}$ without affecting p53 acetylation (Supplementary Fig. 13D). It is interesting to note that TRAIP expression was consistently detected in the DMSO-treated cells upon siRNA interference, and we reasoned that the presence of a compensatory mechanism could potentially stabilize TRAIP and counterbalance the knockdown effect. We postulate that this mechanism could be impaired under cellular stress, thus allowing knockdown of TRAIP to be possible upon drug treatment. However, the detailed mechanism remains elusive at this moment.

To further investigate the mechanisms of the TRAIP/TRAF2/ $\mathrm{NFkB}$ axis, dominant negative IkBa mutants (IkBa- $\Delta \mathrm{N}, \mathrm{IkB}_{\alpha}-$ $\mathrm{S} 32 \mathrm{~A})$ were introduced to shut off $\mathrm{NFkB}$ activity. As expected, dephosphorylation of $\mathrm{IkB}$ in wtp53 cells reduced p-p65, pTRAF2, and c-IAP2 upon drug treatment, recapitulating the effects of TRAIP overexpression (Supplementary Fig. 16A). Surprisingly, transfection of IkBa mutants has little effect in p53-1- cells, and conversely, p65 was highly phosphorylated. Functionally, NFkB inhibition also induced pronounced apoptosis in wtp53 and mutp53 cells, but to a lesser extent in null cells (Supplementary Fig. 16B). Collectively, these data strongly suggest a direct role of TRAIP, expressed upon acetylation of mutp $53^{R 158 G}$, in facilitating apoptosis through disruption of NFkB pathway signaling.

Potent p53 acetylators reduce mutp53 tumor growth. Further analyses of compounds found active against p53 $158 \mathrm{G}$ cells revealed that eight out of the 10 compounds induced $\mathrm{p} 53^{\mathrm{R} 158 \mathrm{G}}$ acetylation (Supplementary Fig. 15A), which was correlated to increased p21, elevated CDKN1A and TRAIP transcripts, suppression of TRAF2 and $\mathrm{p}-\mathrm{IkB}$, as well as augmented PARP cleavage (Supplementary Fig. 15A, D, E), thus supporting our earlier observations. On the contrary, exposure to these acetylators induced stabilization of wtp53 and upregulated p21, increased $M D M 2$ and $C D K N 1 A$ transcripts, but had minimal impact on p-IkB and TRAIP mRNA (Supplementary Fig. 15B-E), thereby highlighting the specificity of these single agents in targeting mutp $53^{\mathrm{R} 158 \mathrm{G}}$ cells.

When applied in vivo, single agent cisplatin was effective in reducing tumor growth of $\mathrm{p} 53^{\mathrm{R} 158 \mathrm{G}}$ xenograft as compared to vehicle, with no efficacy observed in $\mathrm{p} 53^{-1-}$ and $\mathrm{p} 53^{\mathrm{wt}}$ tumors (Supplementary Fig. 16A-C). Of note, efficacy of cisplatin in the p53 $3^{\mathrm{R} 158 \mathrm{G}(\mathrm{K} 20 \mathrm{~A})}$ tumors with defective acetylating mechanism was evidently reduced (Supplementary Fig. 16A-C). Mechanistically, acetylation of mutp53 ${ }^{\mathrm{R} 158 \mathrm{G}}$ was accompanied by elevated TRAIP (Supplementary Fig. 16E), p65 inhibition (Supplementary Fig. 16F) and reduced Ki67 staining, a marker for cellular proliferation (Supplementary Fig. 16G); in contrast with increased p65 nuclear accumulation and lack of efficacy in the wtp53 tumors. Scoring of TRAIP transcripts demonstrated a reciprocal inverse correlation with NFkB activity, for instance, a high basal score was associated 
with low p65 accumulation in p53 tumors (Supplementary Fig. 16H). Further analyses of vehicle- and cisplatin-treated xenograft for drug-activity showed elevated TRAIP mRNA copies in $\mathrm{p} 53^{\mathrm{R} 158 \mathrm{G}}$ tumors, but decrease in wild-type tumors, validating the in vitro data (Supplementary Fig. 16H). We expanded our in vivo studies to screen for efficacy of other potent acetylating agents, as the clinical application of HDACi has been challenging in solid cancers, possibly due to their poor therapeutic index ${ }^{55}$. Whereas volasertib demonstrated high toxicity in mice (died within days of administration), tolerable doses of JQ1 and topotecan were effective in suppressing growth of $\mathrm{p} 53^{\mathrm{R} 158 \mathrm{G}}$ tumors compared to the $\mathrm{p} 53^{\mathrm{wt}}$ and $\mathrm{p} 53^{-1-}$ counterparts (Supplementary Fig. 16I-K), providing direction for future development of p53-acetylating agents in $\mathrm{p}^{\mathrm{R} 158 \mathrm{G}_{\text {-positive }}}$ tumors.

Patient-derived xenograft (PDX) tumors of gastric cancer (GC; p53 $3^{\mathrm{R} 158 \mathrm{C}}$ ) and hepatocellular carcinoma (HCC; p53 $3^{\mathrm{R} 158 \mathrm{H}}$ ) harboring Arg ${ }^{158}$ mutp53 were selected for evaluation with p53-acetylators: cisplatin, JQ1 and topotecan. All three compounds significantly reduced tumor growth in both PDX models (Fig. 7a, b, d, e) at tolerable doses (Fig. 7c, f). Tumor specimens from GC-PDX showed that cisplatin and topotecan significantly induced p53 acetylation and phosphorylation, with TRAIP upregulation as well as PARP cleavage observed in most of the treated tumors (Fig. 7g). Moreover, we demonstrated using RNA in situ hybridization the transcriptional induction of TRAIP mRNA in the drug-treated tumors (Fig. $7 \mathrm{~h}$, i), which was concordant with the protein expression in the matched tumor samples (Fig. 7g). These findings suggest that, while the Arg 158 p53 mutation is more prevalent in lung carcinomas, the mechanism conferring tumor cytotoxicity could be applied across cancer types harboring the same alteration. We further explored the potential of combining a DNA-damaging agent (cisplatin) with an effective p53-acetylating agent (topotecan) in both PDX models. Compared with single agents, combination of cisplatin/ topotecan rapidly and profoundly suppressed tumor growth with no significant weight loss observed in all animals (Fig. 7j), with tumor regression observed in multiple cases (Fig. $7 \mathrm{k}$ ).

\section{Discussion}

Missense mutations in the DNA-binding domain constitute more than $70 \%$ of tumor-associated p53 mutations. These mutations alter DNA-binding capability of mutp53, concomitantly leading to a variable loss of $\mathrm{p} 53$ tumor suppressive functions, while mediating oncogenic GOF through transcriptional aberrations involving chromatin remodeling and interaction with transcription cofactors such as SREBP, ETS2, or NRF2 $2^{6,22,37,56}$. Therapeutic interventions that have been proposed to target mutp53 cells include attempts to exploit the loss of checkpoint function ${ }^{27,28}$, inhibit the GOF pathways 6,29 , and direct destabilization of the mutated protein; 9,10 but these have yet to gain clinical traction. Whether these strategies can be applied globally to all mutp53 remains debatable, as only the six most common "hotspot" mutants have been studied in depth. We studied a GOF $\operatorname{Arg}^{158}$ mutp53 in the DBD found to be relatively frequent in lung carcinomas, and elucidated a unique pathway of mutp53 that can be exploited therapeutically.

The complex crosstalk between p53 and NFkB has been described previously, with the suppression of $\mathrm{p} 65$ in wild-type cells a result of competitive interaction with p300 or glucocorticoid receptor; 48,49 conversely mutp53 prolongs and enhances NFkB activation ${ }^{11,12,57,58}$. We propose here a mechanism for this divergent effect through acetylation of $\operatorname{Arg}^{158}$ mutp53, which alters its DNA-binding spectrum and upregulates TRAIP as key target gene, leading to NFkB suppression through TRAF2 degradation and culminating in cell death (Fig. 8). This p53 isoform appears to carry distinctive GOF mechanisms that does not involve the chromatin regulatory genes as observed in other DBD hotspot mutants; other hotspot p53 mutants, such as $\mathrm{R} 175 \mathrm{H}$ and $\mathrm{R} 273 \mathrm{H}$, did not upregulate TRAIP in response to belinostat and cisplatin treatment. Given that a point mutation is sufficient to affect p53 transactivation ${ }^{59}$, and that protein misfolding regulated by zinc-binding could affect p53 transcriptional functions ${ }^{60}$, it is possible that $\operatorname{Arg}^{158}$ mutp53 modulates sitespecific DNA binding through aberrant Zinc2+ interaction which should be explored further. One possible caveat of the study is the lack of a universal cellular system to distinguish the functions of the various GOF mutp53. The inability to establish a robust CRISPR-Cas9 model has prevented us from studying this.

Our expression analysis and ChIP-Seq findings concordantly demonstrated the retention of transcriptional activity of mutp53 $3^{\mathrm{R} 158 \mathrm{G}}$, which has been described in other DBD variants. Exposure to cellular stress, such as cisplatin, could trigger a partial wild-type activity in mutp53 $3^{\mathrm{R} 158 \mathrm{G}}$ that induces p53-dependent pro-apoptotic signals, which is not seen in p53 null cells. However, the DNA-binding activity of mutp53 ${ }^{\mathrm{R} 158 \mathrm{G}}$ is distinct from p53 $3^{\text {wt }}$, manifesting in GOF activity. Paradoxically, this DNAbinding ability is prerequisite for the induction of apoptosis as initiated through mutp53 ${ }^{\mathrm{R} 158 \mathrm{G}}$ acetylation, a key posttranslational event closely associated with its transcriptional activity and stability ${ }^{61,62}$. Loss of acetylation, particularly at the DBD, significantly impacted cell cytotoxicity, indicating that this post-translational event is indispensable for mutp53 activation. We studied this using in silico modeling of the expected molecular disruptions effected by the acetylation of DBD, and our simulation suggested strongly that the distorted mutp53 conformation could be restored through acetylation within the DBD, which appears to act as a stabilizing factor to facilitate the formation of a functional and stable mutp53 dimers with strong DNA-binding affinity. These further refined the commonly held credence that targeting acetylation and eventual depletion of mutp53 is a plausible anti-tumor approach ${ }^{63}$. Such findings are made therapeutically relevant by positive screen hits for compounds with pharmacological activity of $\mathrm{p} 53^{\mathrm{R} 158 \mathrm{G}}$ acetylation. The selective cytotoxicity of these compounds in $\operatorname{Arg}^{158}$ mutp53 tumors, compared to wild-type and null tumors, is promising as a companion biomarker for selecting patients with greater potential to respond to the p53-acetylating agents. From the therapeutic standpoint, dosages of acetylating agents used in the xenograft experiments were well-tolerated, further heightening the possibility of clinical translation. For instance, the bromodomain (BRD) inhibitor JQ1 is currently in clinical development to target a rare genomic BRD-NUT fusion event in NUT midline carcinoma ${ }^{64}$, and our data extends potential evaluation in $\operatorname{Arg}^{158}$ mutp53 tumors. Curated data from public databases (IARC TP53, COSMICs, ICGC, and cBioportal) reveal the presence of $\operatorname{Arg}^{158}$ mutp53 in multiple carcinomas; and the effectiveness of mutp53 acetylators in the PDX models of gastric and liver cancers further extends the applicability of these findings to other cancer types.

In conclusion, we provide evidence of a unique mechanism of p53 activation that is specific to $\operatorname{Arg}^{158}$ mutations, exposing a previously unrecognized therapeutic vulnerability and facilitating a biomarker-implemented approach directed against this GOF mutant. This is unsurprising, as it has been recently recognized that different p53 mutations are attributable to distinctive phenotypes and cellular effects ${ }^{65,66}$, and our work adds to this. If validated in the clinic, this represents an advance in therapeutic treatment of tumors with mutated p53, particularly that of LUSC, in which $\operatorname{Arg}^{158}$ mutant is found to be prevalent. 
a

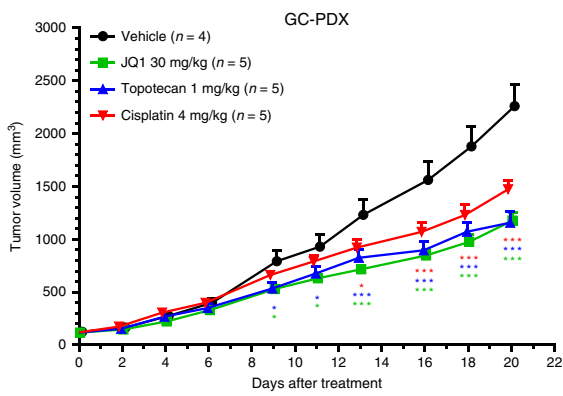

d

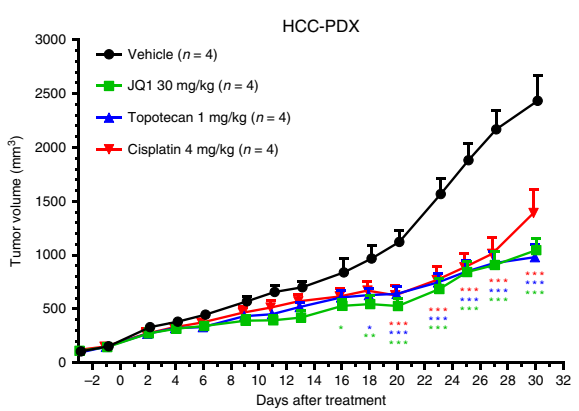

b
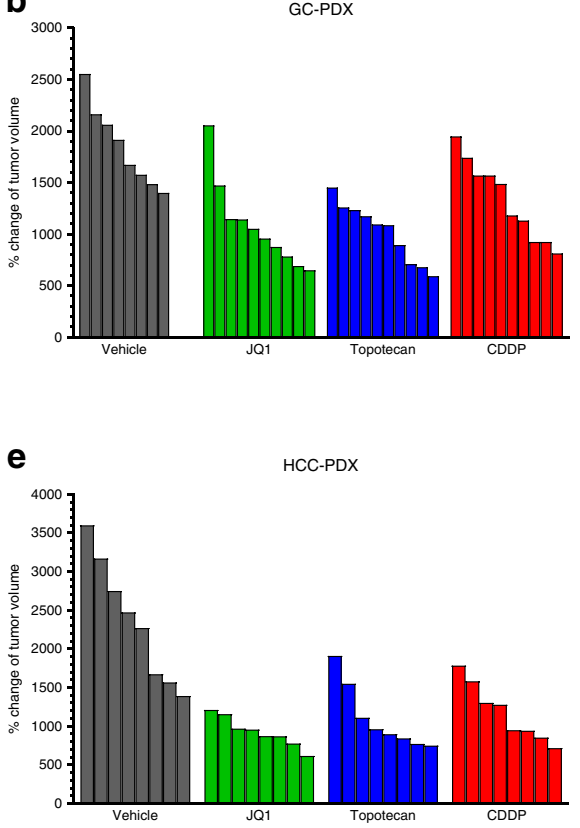

C

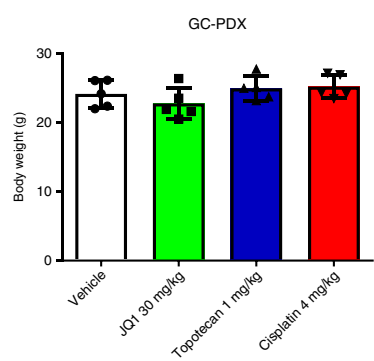

f

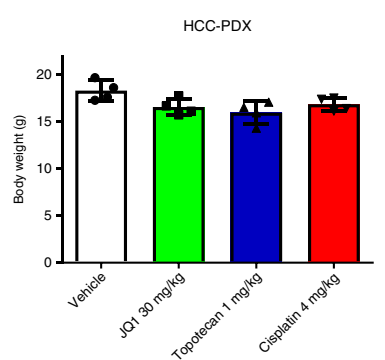

g

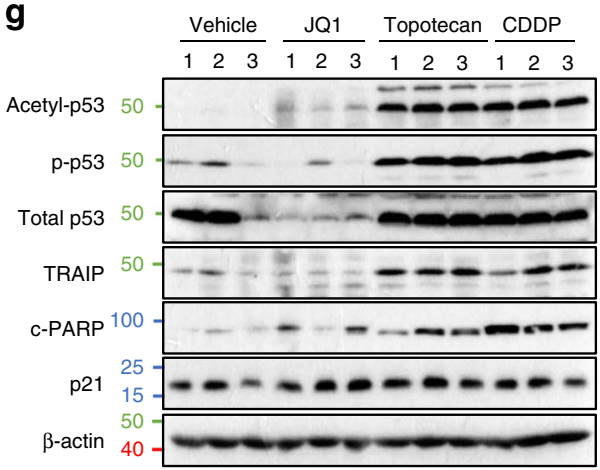

j

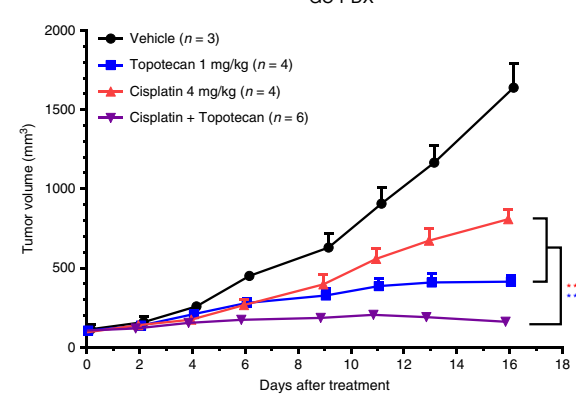

h

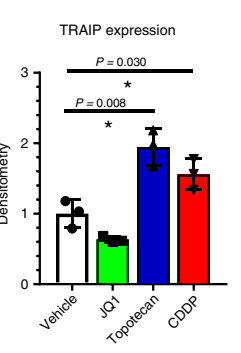

i

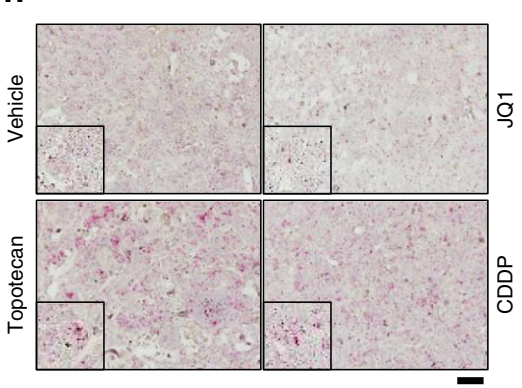

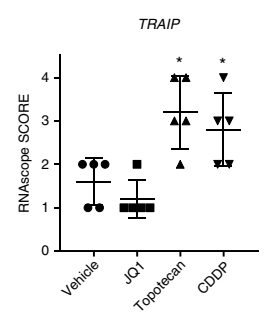
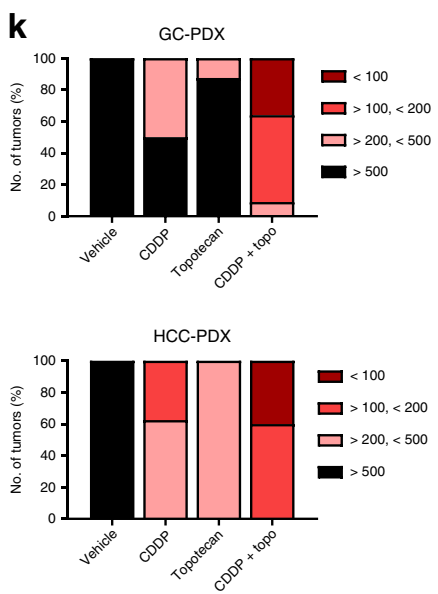

\section{Methods}

Genomic analyses of human cancers. The pan-cancer mutation annotation file were downloaded from GDAC (version 2016_01_28 ${ }^{25}$ ). Mutations found on TP53 genes and the corresponding protein change were extracted for analysis.

Cell culture. Cancer cell-lines (Calu-1, ChaGo-k-1, HCC70, H441, H520, H596, H661, H747, H1417, H2170, MDA-MB-468, SK-BR-3, SK-MES-1) and lung fibroblast cells (MRC-5) were obtained directly from the American Type Culture Collection (ATCC), while others (A549, BT-549, H1975, MIA-Paca-2, PANC-1) were provided by Ashok Venkitaraman (MRC Cancer Unit, Cambridge, UK). Cultures were maintained in a humidified $37^{\circ} \mathrm{C}$ incubator, in culture medium (according to ATCC's recommendation) supplemented with $10 \%$ fetal bovine serum, $2 \mathrm{mM}$ L-glutamine, $100 \mu \mathrm{g} \mathrm{mL}^{-1}$ streptomycin and $100 \mathrm{U} \mathrm{mL}^{-1}$ penicillin. Paired HCT116 $\mathrm{p}^{2} 3^{-1-}$ and $\mathrm{p} 53^{+/+}$cell-lines were obtained from Bert Vogelstein (The John Hopkins Medical School, Baltimore, MD) as a gift. Isogenic Calu-1 cells stably expressing pcDNA3.1 vector, pcDNA3.1-p53wt, pcDNA3.1-p53R158G, pcDNA3.1-p53R158G(DBD, K-A), pcDNA3.1-p53R158G(CT, K-A), pcDNA3.1p53R158G(K20A) plasmids, respectively, were generated by transfection and single-cell selection.

Transwell invasion assay. Matrigel invasion assay was carried out with Corning BioCoat $^{\text {TM }}$ Matrigel Invasion Chambers (\#354480). In brief, 25,000 (for Calu-1) or 50,000 (H2170) cells were plated in the transwell chamber with serum-free medium. For gene silencing experiments, cells were incubated with siRNA overnight 
Fig. 7 Cisplatin, JQ1 and topotecan reduce tumor growth in PDX models harboring Arg $\mathbf{1 5 8}$ p53 mutations. a-f Efficacy of cisplatin, JQ1 and topotecan were investigated in PDX model of gastric cancer (GC) and hepatocellular (HCC) cancer. Growth curve analysis of GC-PDX (a) and HCC-PDX (d) treated with vehicle, cisplatin (CDDP; $\left.4 \mathrm{mg} \mathrm{kg}^{-1}\right)$, JQ1 $\left(30 \mathrm{mg} \mathrm{kg}^{-1}\right)$, or topotecan $\left(1 \mathrm{mg} \mathrm{kg}^{-1}\right)$. Tumor sizes are presented as mean \pm SEM. Two-way ANOVA with Bonferroni correction; ${ }^{\star} P<0.05$; ${ }^{\star \star} P<0.01 ;{ }^{* \star} P<0.001$. Waterfall plots showing change in tumor volume (relative to initial tumor volume at treatmentstart day) for each individual GC-PDX (b) and HCC-PDX (e) tumor in respective treatment group. Bodyweight of mice with GC-PDX (c) and HCC-PDX (f) at assay endpoint was tabulated as mean \pm SD. $\mathbf{g}$ Western blots demonstrating changes of the indicated proteins in tumors of respective treatment $(n=3$ independent tumors). $\beta$-actin shown as loading control. Densitometric quantification of TRAIP expression was tabulated on the right. Relative fold change is normalized to $\beta$-actin, relative to vehicle control tumors. Data presented as mean \pm SD. Two tailed Student's $t$-test; ${ }^{\star} P<0.05$, ${ }^{\star \star} P<0.01$. $\mathbf{h}$-i RNA in situ hybridization (RNAscope) showing TRAIP expression in respective tumors. Representative images showing TRAIP mRNA signal are shown at $\times 20$ magnification (h). Scale bar, $50 \mu \mathrm{m}$. Semi-quantitative scoring (0-4) of TRAIP mRNA signal (dots/cell) in p53wt and p53R158G, respectively, was tabulated (i). Data are represented as scattered dot plot $\pm \mathrm{SD}\left(n=5\right.$ independent tumors). Two tailed Student's $t$-test, ${ }^{\star} P<0.05$. $\mathbf{j}-\mathbf{k}$ Efficacy of cisplatin and topotecan combination were investigated in PDX models of gastric cancer and hepatocellular cancer. $\mathbf{j}$ Growth curve analyses of GC-PDX and HCC-PDX treated with vehicle, cisplatin (CDDP; $\left.4 \mathrm{mg} \mathrm{kg}^{-1}\right)$, topotecan $\left(1 \mathrm{mg} \mathrm{kg}^{-1}\right)$ or CDDP/topotecan combination. Tumor sizes are presented as mean $\pm \mathrm{SEM}$. Two-way ANOVA with Bonferroni correction; ${ }^{\star} P<0.05 ;{ }^{\star \star} P<0.01 ;{ }^{\star \star \star} P<0.001$. $\mathbf{k}$ Change in tumor volume (relative to initial tumor volume at treatmentstart day) for each individual tumor in respective treatment group were calculated and tabulated into four groups $(>500 \% ;>200 \%<500 \%$; $>100 \%$ $<200 \%$; $<100 \%$ ). Tumor volume below $100 \%$ indicates tumor regression.

\section{(a) Acetylated lysine \\ (p) Phosphorylated residues \\ (u) Ubiquitin}

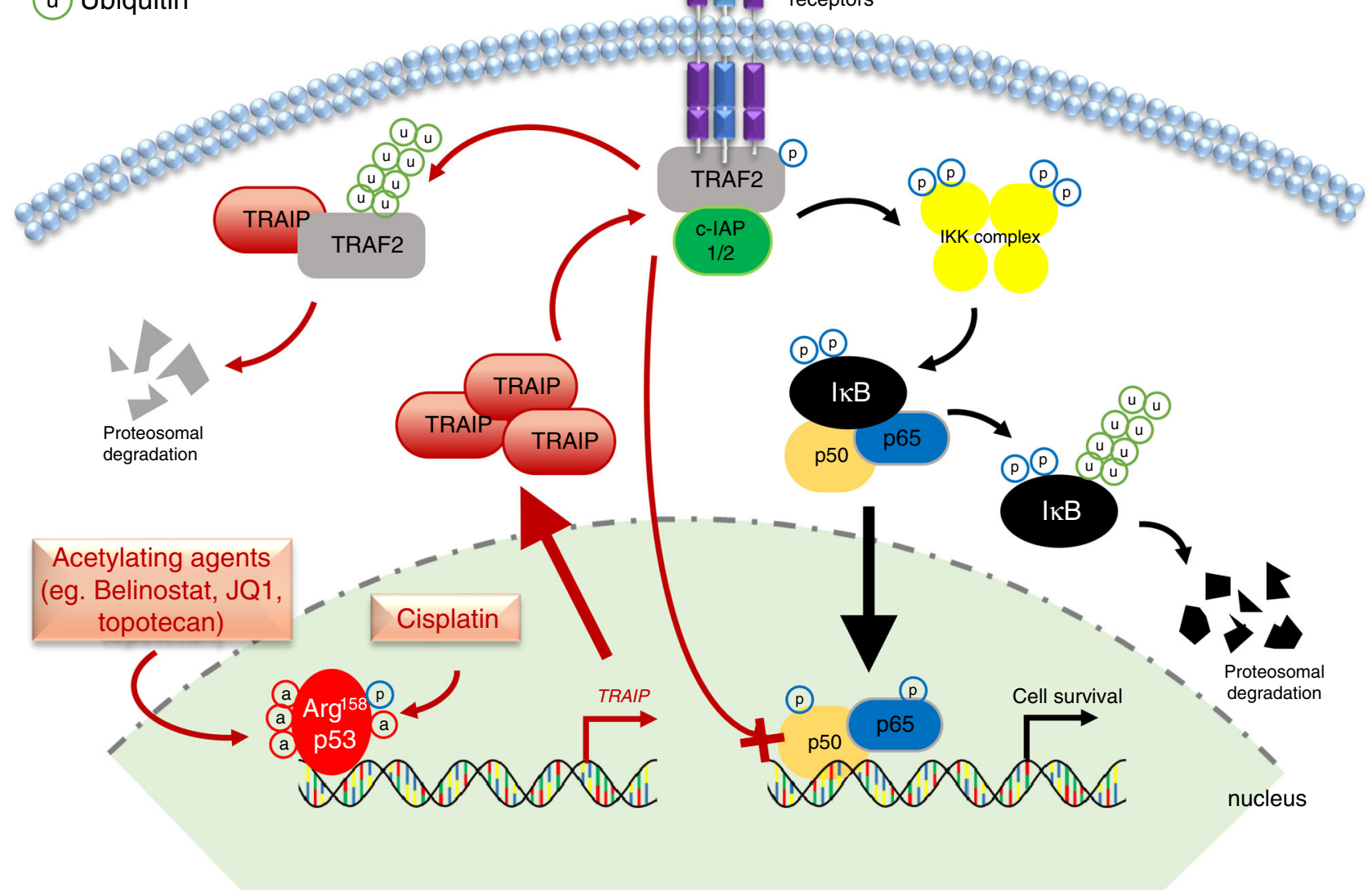

Fig. 8 Proposed mechanism of Arg ${ }^{\mathbf{1 5 8}}$ mutp53 in response to treatment with acetylating agents. Tumor cells harboring mutp53 expressed inherently high level of NFKB activity to confer cellular survival. We showed that in mutp53R158G cells, NFKB/p65 signaling could be suppressed through negative regulation of the TRAF2/C-IAP/ІкB-axis via the upregulation of TRAIP, which is induced transcriptionally by monotherapy or combination treatment of compounds shown to induce mutp53 acetylation.

prior to plating. Tumor cells were allowed to invade for 24-36 hours before the transwell inserts were fixed with $4 \%$ paraformaldehyde, stained with gentian violet and imaged for analysis. Number of invaded cells was quantified with ImageJ Software $(\mathrm{NIH})$, and expressed as mean \pm SD.

Anchorage-independent soft agar assay. The colony forming assay comprises three layers of soft agar/medium matrix in 24-well plate: a bottom layer of $0.6 \%$ agar matrix; a middle layer containing $0.36 \%$ agar matrix with the indicated cells
(10,000 cells/well); and a top layer comprising complete medium. Culture medium were changed weekly. For gene silencing experiments, cells were incubated with siRNA overnight prior to culturing in soft agar. After 4 weeks of culture, colonies were stained with MTT stain (Promega, \#G4000) for $2 \mathrm{~h}$ and imaged. Colonies were counted with ImageJ Software, and expressed as mean \pm SD.

PCR and sequencing. Total RNA was isolated from cells using RNeasy kit (Qiagen, \#74106) and reverse-transcribed to cDNA using iScript RT Supermix 
(Bio-Rad, \#1708841). Sanger sequencing were carried out on amplified DNA to sequence region of interest according to standard protocol. Real-time qPCR was performed in triplicates using standard procedures on a $7500 \mathrm{HT}$ Fast-Real-Time PCR platform (ABI), using probe-based assays. Gene expressions were normalized to the housekeeping gene GAPDH. ChIP was performed using Active Motif ChIPIT ChIP-seq kit according to manufacturer's protocol with slight modifications. In brief, cells were crosslinked with $1 \%$ formaldehyde, glycine quenched, lysed with cell lysis buffer (Sigma, \#2978) supplemented with $1 \mathrm{mM}$ PMSF, and subjected to pulse sonication ( $20 \mathrm{~s}$ with $30 \mathrm{~s}$ internal, five cycles). The supernatant was then immunoprecipitated with the p53 and rabbit IgG antibodies (Cell Signaling, \#9282 and \#2729) at $4{ }^{\circ} \mathrm{C}$ overnight and incubated with Magna ChIP Protein G magnetic beads (Millipore, \#16-662). The beads were washed before DNA was reversecrosslinked and purified. For ChIP-Seq, sequencing libraries were prepared using TruSeq DNA LT Sample Prep kits, and pair-end sequencing was performed on Illumina Hi-Seq platform. ChIP-qPCR validation was performed in triplicates using standard procedures on a 7500HT Fast-Real-Time PCR platform (ABI), using primer-based assays. For Ion AmpliSeq Transcriptome Human Gene Expression (Thermo Fisher), 10 ng RNA was used for barcoded cDNA library preparation using PCR-based targeted-amplicon amplification according to man ufacturer's protocol. Pooled libraries were amplified with emulsion PCR on Ion Torrent OneTouch2 instruments (OT2) and sequenced on Ion Torrent Proton sequencing system. Both Hi-Seq and AmpliSeq were performed at AITbiotech (Singapore), Sanger sequencing at Axil Scientific (Singapore). All primer sequences used for RT-qPCR and ChIP-qPCR in this study are tabulated in Supplementary Table 5.

Chemical screening, compounds, cell viability assay. Selleckchem Anti-cancer compound Library (414 compounds, \#L3000), Enzo Epigenetic Library (43 modulators, \#BML-2836) and Selleckchem Epigenetic Library (151 modulators, \#L1900) were used for high-throughput chemical screening. Bleomycin (S1214), AZD7762 (S1532), cladribine (S1199), topotecan (S1231), nocodazole (S2775), volasertib (S2235), BI-2536 (S1109), 17-AAG (S1141), belinostat (PXD101, S1085), bosutinib (S1014), MK-5108 (S2770), JQ1 (S7110), CX-6258 (S7041), alisertib (S1133), JNJ-26481585 (S1096), and M344 (S2779) were purchased from Selleckchem; oxamflatin was purchased from Sigma Aldrich (O3139). All compounds were dissolved in Dimethyl sulfoxide (DMSO, Sigma Aldrich, \#D8418). Cisplatin was obtained from Hospira Pharmaceuticals. Approximately 3000/1000 cells were seeded per well into a 96/384-well plate $24 \mathrm{~h}$ prior to drug treatment. For highthroughput studies, cultures were dispensed $(50 \mu \mathrm{L})$ into 384-well plates using a MultiFlo dispenser, while drugs were 100 -fold diluted in DMSO and kept at $1 \%(\mathrm{v} /$ v) across all drug concentrations and control. The cell viability was assayed at $72 \mathrm{~h}$ post-treatment using either CellTiter-Glo luminescent or CellTiter-96 Aqueous One cell viability reagent (Promega, \#G7572 and G3582). The luminescence signals were detected using TECAN Infinite M1000 pro multi-mode plate reader using an integration time of 1000/250 ms. Absorbance was recorded at $490 \mathrm{~nm}$. The relative luminescence/absorbance units from treated wells were normalized against DMSO control wells and expressed as percentage cell viability. $\mathrm{IC}_{50}$ values were calculated using GraphPad Prism software.

Drug screening bioinformatics, Bliss Independent index. Drug response of the Calu-1 cell-lines were quantified using the Inhibition score (I-score). For each compound $c$, the $I$-score was determined as follows:

$$
I-\operatorname{score}(c)=\left(1-\frac{\text { Luminescence signal }(c)}{\text { Median of Luminescence signal(DMSO })}\right) \times 100
$$

where the denominator is the median of the luminescence emitted in presence of Dimethy sulfoxide (DMSO). The inhibition heatmap of selected drugs (filtered at $I$-score $>50$ in at least one of the cell-lines) between the Calu-1 wild-type, mutant and null cell-lines were hierarchically clustered using complete linkage clustering and Euclidean distance measure. Combination Index (CI) was calculated based on the Bliss Independence model, by considering all dose combinations tested (observed combination response against the predicted combination response). By assuming that there is not drug-drug interaction, the combination effect is declared synergistic if the observed response is greater than the predicted response $($ Bliss $<0)$.

Western blotting, cellular fractionation, and antibodies. The sodium dodecyl sulfate-PAGE (SDS-PAGE) was performed as described previously ${ }^{67}$. Whole-cell lysates were extracted with cell lysis buffer (Sigma, \#2978) supplemented with protease and phosphatase inhibitors (ThermoFisher, \#78440). Protein concentration was determined by BCA protein assay (Life Technologies, \#23227), and equal amount of proteins were separated using SDS-PAGE. Cytosolic and nuclear fractionations were performed according to manufacturer's protocol (Active Motif, \#40010). The ratio of cytoplasmic to nuclear proteins was 3:1 for Western blotting.

Antibodies used for immunoblotting include: PARP (\#9542), cleaved PARP (\#5625), caspase 3 (\#9662), caspase 7 (\#9492), acetyl-H3K23 (\#9674), acetylH3K9K14 (\#9677), total H3 (\#9715), phospho-p53 Ser15 (\#9286), acetyl-p53 Lys 382 (\#2525), acetyl-p53 Lys379 (\#2570), total p53 (\#9282), p21 (\#2947), $\gamma \mathrm{H} 2 \mathrm{AX}$ (\#9718), phopho-IкB Ser32 (\#2859), total IкB (\#9247), total p65 (\#8242), phoshphTRAF2 Ser11 (\#13908), total TRAF2 (\#4724), c-IAP1 (\#7065), c-IAP2 (\#3130), $\alpha$-tubulin (\#2125), and horseradish peroxidase (HRP)-conjugated $\beta$-actin (\#5125) antibodies as well as secondary anti-mouse (\#7076) and -rabbit (\#7074) HRPconjugated secondary antibodies were obtained from Cell Signaling Technologies; acetyl-H4 (\#06-866) antibody was from Merck Millipore; TRAIP (\#ab80170), TATA-box binding protein (\#ab818) were from Abcam; DDK (\#TA180144) antibody was from Origene. All antibodies were used at 1:2000 dilution.

Caspase activity, apoptosis and cell cycle assays. Caspase 3/7 enzyme activities were measured by using Caspase-Glo 3/7 Assay Systems (Promega, \#G8090) according to manufacturer's protocol. Cells were incubated with indicated compounds for $24 \mathrm{~h}$, and the luciferase activities were measured after substrate incubation with a TECAN Infinite plate reader. Apoptosis assay was carried out using annexin V-APC (Thermo Fisher, \#A35110) and propidium iodide (PI, BD Biosciences, \#556463) according to manufacturer's protocol. In brief, harvested cells $\left(0.2 \times 10^{6}\right)$ were washed with PBS followed by annexin V buffer (Thermo Fisher, \#V13246), and stained with Annexin V/PI mixture for $15 \mathrm{~min}$ at $25^{\circ} \mathrm{C}$. Cell cycle fractions were determined through PI nuclear staining. In brief, harvested cells $\left(0.2 \times 10^{6}\right)$ were fixed with $70 \%$ cold ethanol, and stained with PI staining buffer (0.03 mg ml $\mathrm{m}^{-1}$ PI, $0.1 \mathrm{mg} \mathrm{ml}^{-1}$ RNAse A, $0.1 \%$ Triton-X in PBS) for $30 \mathrm{~min}$ at $25^{\circ} \mathrm{C}$. The staining profile was acquired $(\geq 10,000$ cell events) using LSR II Flow Cytometer (BD Biosciences). The acquisition was analyzed using the FlowJo 8.1.1 software (Tree Star).

Plasmids and transfection. For stable overexpression in Calu- 1 cells, wtp53 (pcDNA3.1-p53wt) and mutp53 (pcDNA3.1-p53R158G) sequences were cloned from MRC-5 and H2170 cell-lines, respectively, while site-directed mutagenesis was performed for substitution of Lysine residues to Alanine in the indicated plasmids [pcDNA3.1-p53R158G(DBD, K-A), pcDNA3.1-p53R158G(CT, K-A), pcDNA3.1-p53R158G(K20A)] using QuikChange Lightning Kit (Agilent, \#210519). For stable knockdown of p53, H2170 cells were transfected with pLKO.1-puro Non-Target shRNA Control (shNT, Sigma Aldrich, SHC016), pLKO.1-puro Luciferase shRNA Control (shLuc, Sigma Aldrich, \#SHC007), or shRNAs targeting TP53 (gifts from Cheok CF, IMCB, A*Star, Singapore). For transient overexpression, pCMV6-Entry vector and pCMV6-TRAIP-DDK was obtained from Origene, while $\mathrm{pCMV}-\mathrm{I \kappa B}(\Delta \mathrm{N})$ and pCMV-IкB(S32A) are gifts from Pieter Johan Adam Eichhorn (Cancer Science Institute of Singapore). Plasmid transfections were carried out with FuGENE HD (Promega, \#E2311). For transient gene knockdown, TP53 siRNA (sequence: 5'-ACUCCACACGCAAAUUUCCTT3'), TRAIP siRNA (sequence: 5'-UUACACCUCAGGCUGGUCCCG-3') and AllStar negative control siRNA were obtained from Qiagen. siRNA transfection was conducted with JetPRIME reagent (Polyplus Transfection).

Reporter-luciferase assay. The transcriptional activity of p53 was assessed by reporter-luciferase assay. Cells were co-transfected with a combination of Cignal reporter plasmids (Qiagen, \# CCS-004L), including a mixture of inducible p53responsive firefly luciferase construct or non-inducible firefly luciferase construct, with constitutively expressing Renilla luciferase construct. The cells were then drug treated for the indicated durations, and luciferase assay was performed with Dual Luciferase Reporter Assay System (Promega, \#E1910) according to manufacturer's instructions and detected by Lumat LB 9507 (Berthold Technologies). The ratio between Renilla luciferase across samples was used to normalize the transfection efficiency.

In vitro translation (IVT), acetylation, and EMSA. IVT was performed according to manufacturer's protocol (Thermo Scientific, \#88881). Briefly, $1 \mu \mathrm{g}$ each of pcDNA3.1-p53wt and pcDNA3.1-p53R158G plasmids were incubated with the Hela extract and reaction mix for $6 \mathrm{~h}$ at $30^{\circ} \mathrm{C}$. The in vitro protein acetylation (IVA) assay was performed, with a standard reaction included half of the sample from the IVT assay, $0.5 \mu \mathrm{g}$ of histone acetyltransferase domain of p300/CBP protein (Upstate, \#14-418), $4 \mu \mathrm{g}$ of Acetyl-CoA (Sigma, \#A2056) and diluted in assay buffer (final concentration of $50 \mathrm{mM}$ Tris-HCl, $\mathrm{pH}$ 8.0, 10\% glycerol, $0.1 \mathrm{mM}$ EDTA, $1 \mathrm{mM}$ dithiothreitol). The reaction mix was incubated for $6 \mathrm{~h}$ at $30^{\circ} \mathrm{C}$ in a shaking incubator. The expression and acetylation of the respective p53 proteins were validated with immunoblotting.

Electrophoretic mobility shift assay (EMSA) was conducted according to manufacturer's protocol (Thermo Scientific, E33075). 31-mer oligo containing p53 response element of CDKN1A gene (5'-CAGCATGCTCCAGGTAGAAGGAAA CAGGCCC-3') was ordered from IDT. Briefly, $50 \mathrm{ng}$ of the synthesized oligos was incubated with $2 \mu \mathrm{l}$ of the reaction containing the respective p53 isoforms, and incubated for $2 \mathrm{~h}$ at $30^{\circ} \mathrm{C}$. The samples were then separated by PAGE using $6 \%$ non-denaturing gel. DNA and protein were stained simultaneously with SYBR Green nucleic acid gel stain and SYPRO ${ }^{\circ}$ Ruby protein gel stain, respectively. The images were then visualized and captured using UV transilluminator.

Molecular dynamics simulations of p53. The dimeric structure of the p53 DNABinding Domain (DBD) complexed to a small fragment of DNA (PDB ID: 2AHI) was taken from the RCSB Protein Data Bank. Molecular dynamics (MD) simulations of the p53-DBD ${ }^{\mathrm{WT}}, \mathrm{p} 53-\mathrm{DBD}^{\mathrm{R} 158 \mathrm{G}}$, and acetylated Lysine $\mathrm{p} 53-\mathrm{DBD} \mathrm{D}^{\mathrm{R} 158 \mathrm{G}}$ were carried out with the pemed.CUDA module of the program Amber16 with the 
Amber 14SB force field (ff14SB). Force field parameters for acetylated Lysine were taken as described previously ${ }^{68}$. The Xleap module was used to prepare the system for the MD simulations. All the simulation systems were neutralized with appropriate numbers of counterions. Each neutralized system was solvated in an octahedral box with TIP3P water molecules, leaving at least $10 \AA$ between the solute atoms and the borders of the box. All MD simulations were carried out in explicit solvent at $300 \mathrm{~K}$. During the simulations, the long-range electrostatic interactions were treated with the particle mesh Ewald method using a real space cutoff distance of $9 \AA$. The Settle algorithm was used to constrain bond vibrations involving hydrogen atoms, which allowed a time step of $2 \mathrm{fs}$ during the simulations. Solvent molecules and counterions were initially relaxed using energy minimization with restraints on the protein and inhibitor atoms. This was followed by unrestrained energy minimization to remove any steric clashes. Subsequently the system was gradually heated from 0 to $300 \mathrm{~K}$ using MD simulations with positional restraints (force constant: $50 \mathrm{kcal} \mathrm{mol}^{-1} \AA^{-2}$ ) on the protein over a period of $0.25 \mathrm{~ns}$ allowing water molecules and ions to move freely. During an additional $0.25 \mathrm{~ns}$, the positional restraints were gradually reduced followed by a 2 ns unrestrained MD simulation to equilibrate all the atoms. Production simulations were carried out for $250 \mathrm{~ns}$ each in triplicates. Enhanced conformational sampling was carried out by subjecting the systems to accelerated MD (aMD) implemented in AMBER 16, using the "dual-boost" version. Conventional MD simulations carried out earlier were used to derive the aMD parameters (EthreshP, alphaP, EthreshD, alphaD). aMD simulations were carried out for $250 \mathrm{~ns}$ each. Simulation trajectories were visualized using VMD and figures were generated using Pymol.

\section{Chromatin immunoprecipitation (ChIP)-seq, AmpliSeq analyses. At least 16} million 51-bp long reads were mapped to hg19 using bowtie v2.1.0 with parameters -N 1 -sensitive -p 2 -no-unal. Peaks were identified by MACS 2.0.9 using a maximum of 2 reads per unique position and otherwise default parameters. Only highly enriched (enrichment over background $\geq 5$-fold, pileup $\geq 25$ ) and highly significant ( $q$-value $<0.01$ ) peaks were shortlisted from the analysis. de novo motif search was conducted by MEME-ChIP54 using the TSS proximal peaks center extended by $75 \mathrm{bp}$ in both directions to determine the distribution of wtp53 and mutp53-binding sites post-treatment with reference to hg19 annotations. MEME was programmed to search for the top 10 motifs with significant matches between query and target database using HOMER (Hypergeometric Optimization of Motif EnRichment) $55 \mathrm{v} 4.5$. The heatmaps of p53 enrichments (wtp53 and mutp53R158G) across $3 \mathrm{~kb}$ region from peak centre were plotted using ngsplot, v2.61. For AmpliSeq, fastq files were analyzed with the ampliSeqRNA plugin available for Ion Torrent sequencing platforms that used the Torrent Mapping Alignment Program (TMAP). TMAP first identify a list of Candidate Mapping Locations (CMLs) and aligned with Smith Waterman algorithm for specific and sensitive mapping. DEG analysis was performed using R/Bioconductor package DESeq2, with read count normalized to produce differential gene expressions as determined by $p$-value and the $\log _{2}$ fold change. GEO superSeries: GSE129027.

Comet assay. Comet assay was performed using OxiSelect 96-well kit (Cell Biolabs, \#STA-355) according to manufacturer's recommendation. Briefly, treated cells were trypsinized and mixed with low melting-point agarose at $37^{\circ} \mathrm{C}$. Cells/agarose mixture was quickly placed onto pre-coated 96 -well Comet slide, and cooled at $4{ }^{\circ} \mathrm{C}$ to solidify the agarose layer. The ready slide was treated with hypertonic lysis buffer, and followed by incubation with alkaline buffer to unwind DNA strands and expose the alkali labile sites (comet tails), which were imaged by fluorescence microscopy at $\times 20$ magnification (Olympus IX71/DP71). Olive Tail Moment (OTM) was quantified using ImageJ software (NIH, 1.51n) with OpenComet plugin, using the formula OTM $=$ (mean Tail-Intensity - mean Head-Intensity) $\mathrm{X}$ Tail\%DNA/100. The mean \pm S.D. of OTM from at least 50 cells in each treatment group was quantified.

Nuclear NFKB activity assay. Activation of nuclear NFkB p65 subunit was quantified in nuclear protein extracts using the ELISA-based TransAM p65 NF-kB Kit (Active Motif, \#40596) according to manufacturer's recommendation. Cellular fractionation was performed as described, and absorbance measurements $(450 \mathrm{~nm})$ on nuclear extracts $(5 \mu \mathrm{g})$ in triplicates were performed using TECAN Infinite plate reader.

\section{High-content microscopy and immunofluorescence imaging. Cultured cells} were fixed with methanol for $30 \mathrm{~min}$, and immunostained with acetyl-p53 (1:500, Cell Signaling, \#2570), p-p53 (1:500, Cell Signaling, \#9286), or NF-kB p65 (1:1000, Cell Signaling, \#8242) for 4 hours at $4{ }^{\circ} \mathrm{C}$, followed by incubation with Alexa Fluor488 or -594 secondary antibodies (1:1000, Molecular Probes, Life Technologies, A11034 and R37121) for $2 \mathrm{~h}$ at $25^{\circ} \mathrm{C}$, and by Hoechst 33342 nuclear staining (1:2000, Sigma, \#23491-52-3) for $15 \mathrm{~min}$. Imaging of 96-well plate was performed using a high-content imaging system (MetaXpress Ultra, Molecular Devices) with $\times 40$ objective. Airyscan super-resolution confocal images were acquired with LSM800 (Zeiss Germany) with $\times 63$ objective. Image analyses were conducted using the Color Deconvolution Plugin in ImageJ software (NIH; 1.51n $)^{69}$.
Tumor xenograft assay. All in vivo xenograft studies adhered to the SingHealth Animal Care and Use Committee (IACUC) guidelines on animal use and handling. Usage of patient-derived materials have been approved by SingHealth Institutional Review Board (IRB). All tumor xenografts were established in male C.B-17 SCID mice aged 9-10 weeks and weighed 23-25 g (InVivos Pte. Ltd., Singapore). Mice were provided with sterilized food and water ad libitum, and housed in negative pressure isolators, which were set at $23^{\circ} \mathrm{C}$ and $43 \%$ humidity, with 12 -h light/dark cycles.

In brief, $10 \times 10^{6}$ isogenic Calu- 1 cells (empty vector control, wtp53, mutp53) in $100 \mu \mathrm{L}$ of PBS or $1-2 \mathrm{~mm}^{3}$ dices of PDX tumors (GC-PDX and HCC-PDX) were injected subcutaneously into the flanks of each mice. Tumor size was monitored and measured three times weekly with Vernier calipers (tumor volume $=$ length $\times$ width $\left.{ }^{2} \times 3.14159 / 6\right)$. For inhibitor studies, mice were assigned into stratified groups based on average tumor volume ( $n=5$ animals/10 tumors per group). Treatment began when the tumor sizes reached $\sim 200 \mathrm{~mm}^{3}$. Cisplatin was provided in $0.9 \%$ $\mathrm{NaCl}$ and given at $4 \mathrm{mg} \mathrm{kg}^{-1}$ by intraperitoneal (ip), once weekly for 3 weeks. JQ1 and topotecan were formulated in 30\% (w/v) Captisol and $30 \%(\mathrm{w} / \mathrm{v})$ PEG300 at $30 \mathrm{mg} \mathrm{kg}^{-1}$ and $1 \mathrm{mg} \mathrm{kg}^{-1}$, respectively, and given via PO (orally), 7 days a week. Bodyweight at sacrifice and tumor samples were collected 3 weeks after treatment commenced.

\section{Immunohistochemistry (IHC), RNA in situ hybridization (ISH). Xenograft} tumors from control and compounds administered mice were fixed in formalin after surgical excision overnight, and embedded in paraffin and sectioned $(4 \mu \mathrm{m})$. Tumor sections were deparaffinized using standard histologic procedures prior to antigen retrieval. For IHC, slides were incubated with primary antibodies [NF-kB p65 (1:1000, Cell Signaling, \#8242), cleaved caspase 3 (1:1000, Cell Signaling, \#9661), Ki67 (1:1000, Abcam, \#ab15580) overnight at $4{ }^{\circ} \mathrm{C}$. Color development was performed using EnVision+ System-HRP (DAB) kit (Dako, Agilent Technologies) according to the manufacturer's protocol. Single molecule mRNA ISH (RNAscope, ACD Biotech) was performed using the Advanced Cell Diagnostics RNAscope 2.5 HD Detection kit (\#322360) according to manufacturer's recommendation. TRAIP probe was customized. For both IHC and RNAscope, cell nuclei were counterstained with Hematoxylin (Thermo Scientific, \#72604). Slide images were captured under optical imaging microscope at $\times 20$ magnification (Olympus IX71/DP71). Images were acquired from five tumor samples each for every treatment group, and analyzed with ImageJ software using an image processing workflow described previously ${ }^{67}$. Briefly, Hematoxylin and DAB/Fast Red color-separated images were derived from the original image using ImageJ Color Deconvolution plugin. Object segmentation using the Particle Analyzer plugin was then performed to identify the individual cellular regions in each image, and the signal intensity (DAB) or count (Fast Red) in the image was then tabulated. IHC staining was analyzed as the percentage of DAB-positive cells/100 cells in each slide image. RNA-ISH staining was scored based on the number of positive signal in each cell ( 0 : no staining or $<1$ dot/ 10 cells; $1: 1-3$ dots/cell; 2: 4-9 dots/cell; 3: 10-15 dots/cell; 4: $>15$ dots/cell). At least 20 images were analyzed for each tumor sample.

Statistics, data reporting, and reproducibility. No statistical method was applied to predetermine sample size. All experiments were conducted three times unless stated otherwise. Data that could be reproduced in biological replicates were reported. Statistical analysis for the comparison between two groups was conducted using Student's $t$-test, while comparisons between multiple groups was conducted using two-way ANOVA post-hoc tests.

Reporting summary. Further information on research design is available in the Nature Research Reporting Summary linked to this article.

\section{Data availability}

The ChIP-seq and AmpliSeq datasets generated during the current study have been deposited in GEO with the Accession number GSE129027 and could be accessed at this link: https://www.ncbi.nlm.nih.gov/geo/query/acc.cgi?acc=GSE129027. All the other data supporting the findings of this study are available within the article and its supplementary information files and from the corresponding author upon reasonable request. A reporting summary for this article is available as a Supplementary Information file.

Received: 4 March 2019; Accepted: 19 March 2020; Published online: 29 April 2020

\section{References}

1. Lawrence, M. S. et al. Discovery and saturation analysis of cancer genes across 21 tumour types. Nature 505, 495-501 (2014).

2. Zerdoumi, Y. et al. Drastic effect of germline TP53 missense mutations in LiFraumeni patients. Hum. Mutat. 34, 453-461 (2013). 
3. Barak, Y., Juven, T., Haffner, R. \& Oren, M. mdm2 expression is induced by wild type p53 activity. EMBO J. 12, 461-468 (1993).

4. Haupt, Y., Maya, R., Kazaz, A. \& Oren, M. Mdm2 promotes the rapid degradation of p53. Nature 387, 296-299 (1997).

5. Park, D. J. et al. Transactivational and DNA binding abilities of endogenous p53 in p53 mutant cell lines. Oncogene 9, 1899-1906 (1994).

6. Freed-Pastor, W. A. et al. Mutant p53 disrupts mammary tissue architecture via the mevalonate pathway. Cell 148, 244-258 (2012).

7. Lang, G. A. et al. Gain of function of a p53 hot spot mutation in a mouse model of Li-Fraumeni syndrome. Cell 119, 861-872 (2004).

8. Hanel, W. et al. Two hot spot mutant p53 mouse models display differential gain of function in tumorigenesis. Cell Death Differ. 20, 898-909 (2013).

9. Li, D., Marchenko, N. D. \& Moll, U. M. SAHA shows preferential cytotoxicity in mutant $\mathrm{p} 53$ cancer cells by destabilizing mutant p 53 through inhibition of the HDAC6-Hsp90 chaperone axis. Cell Death Differ. 18, 1904-1913 (2011).

10. Alexandrova, E. M. et al. Improving survival by exploiting tumour dependence on stabilized mutant p53 for treatment. Nature 523, 352-356 (2015).

11. Cooks, T. et al. Mutant p53 prolongs NF-kappaB activation and promotes chronic inflammation and inflammation-associated colorectal cancer. Cancer Cell 23, 634-646 (2013).

12. Weisz, L. et al. Mutant $\mathrm{p} 53$ enhances nuclear factor kappaB activation by tumor necrosis factor alpha in cancer cells. Cancer Res. 67, 2396-2401 (2007).

13. Brázdová, M. et al. Modulation of gene expression in U251 glioblastoma cells by binding of mutant p53 R273H to intronic and intergenic sequences. Nucleic Acids Res. 37, 1486-1500 (2009).

14. Gohler, T. et al. Mutant p53 proteins bind DNA in a DNA structure-selective mode. Nucleic Acids Res. 33, 1087-1100 (2005).

15. Gaiddon, C., Lokshin, M., Ahn, J., Zhang, T. \& Prives, C. A subset of tumorderived mutant forms of p53 down-regulate p63 and p73 through a direct interaction with the p53 core domain. Mol. Cell Biol. 21, 1874-1887 (2001)

16. Gao, J. et al. Integrative analysis of complex cancer genomics and clinical profiles using the cBioPortal. Sci. Signal 6, pl1 (2013).

17. Cerami, E. et al. The cBio cancer genomics portal: an open platform for exploring multidimensional cancer genomics data. Cancer Disco. 2, 401-404 (2012).

18. Cancer Genome Atlas Research N. Comprehensive genomic characterization of squamous cell lung cancers. Nature 489, 519-525 (2012).

19. Cancer Genome Atlas Research N. Comprehensive molecular profiling of lung adenocarcinoma. Nature 511, 543-550 (2014).

20. Olive, K. P. et al. Mutant p53 gain of function in two mouse models of LiFraumeni syndrome. Cell 119, 847-860 (2004).

21. Di Agostino, S. et al. Gain of function of mutant p53: the mutant p53/NF-Y protein complex reveals an aberrant transcriptional mechanism of cell cycle regulation. Cancer Cell 10, 191-202 (2006).

22. Zhu, J. et al. Gain-of-function p53 mutants co-opt chromatin pathways to drive cancer growth. Nature 525, 206-211 (2015).

23. Liu, D. P., Song, H. \& Xu, Y. A common gain of function of $\mathrm{p} 53$ cancer mutants in inducing genetic instability. Oncogene 29, 949-956 (2010).

24. Ahrendt, S. A. et al. p53 mutations and survival in stage I non-small-cell lung cancer: results of a prospective study. J. Natl Cancer Inst. 95, 961-970 (2003).

25. Broad Institute TCGA Genome Data Analysis Center. Analysis Overview for 28 January 2016, Broad Institute of MIT and Harvard. https://doi.org/10.7908/ C1K9371X (2016).

26. Vogiatzi, F. et al. Mutant p53 promotes tumor progression and metastasis by the endoplasmic reticulum UDPase ENTPD5. Proc. Natl Acad. Sci. USA 113, E8433-E8442 (2016)

27. Yeo, C. Q. et al. p53 maintains genomic stability by preventing interference between transcription and replication. Cell Rep. 15, 132-146 (2016).

28. Bunz, F. et al. Disruption of p53 in human cancer cells alters the responses to therapeutic agents. J. Clin. Invest. 104, 263-269 (1999).

29. Muller, P. A. et al. Mutant p53 drives invasion by promoting integrin recycling. Cell 139, 1327-1341 (2009).

30. Wahl, A. F. et al. Loss of normal p53 function confers sensitization to Taxol by increasing G2/M arrest and apoptosis. Nat. Med. 2, 72-79 (1996).

31. Yim, H. Current clinical trials with polo-like kinase 1 inhibitors in solid tumors. Anticancer Drugs 24, 999-1006 (2013).

32. Lee, H. Z. et al. FDA approval: belinostat for the treatment of patients with relapsed or refractory peripheral T-cell lymphoma. Clin. Cancer Res. 21, 2666-2670 (2015).

33. Jackson, J. G. et al. p53-mediated senescence impairs the apoptotic response to chemotherapy and clinical outcome in breast cancer. Cancer Cell 21, 793-806 (2012).

34. Xu, W. S., Perez, G., Ngo, L., Gui, C. Y. \& Marks, P. A. Induction of polyploidy by histone deacetylase inhibitor: a pathway for antitumor effects. Cancer Res. 65, 7832-7839 (2005).

35. Paul, I. et al. Acquired differential regulation of caspase- 8 in cisplatin-resistant non-small-cell lung cancer. Cell Death Dis. 3, e449 (2012).
36. Lain, S. et al. Discovery, in vivo activity, and mechanism of action of a smallmolecule p53 activator. Cancer Cell 13, 454-463 (2008).

37. Do, P. M. et al. Mutant p53 cooperates with ETS2 to promote etoposide resistance. Genes Dev. 26, 830-845 (2012).

38. Soo Lee, N. et al. TRAIP/RNF206 is required for recruitment of RAP80 to sites of DNA damage. Nat. Commun. 7, 10463 (2016).

39. Harley, M. E. et al. TRAIP promotes DNA damage response during genome replication and is mutated in primordial dwarfism. Nat. Genet. 48, 36-43 (2016).

40. Shinohara, A., Ogawa, H. \& Ogawa, T. Rad51 protein involved in repair and recombination in S. cerevisiae is a RecA-like protein. Cell 69, 457-470 (1992).

41. Besse, A., Campos, A. D., Webster, W. K. \& Darnay, B. G. TRAF-interacting protein (TRIP) is a RING-dependent ubiquitin ligase. Biochem. Biophys. Res. Commun. 359, 660-664 (2007).

42. Lee, S. Y., Lee, S. Y. \& Choi, Y. TRAF-interacting protein (TRIP): a novel component of the tumor necrosis factor receptor (TNFR)- and CD30-TRAF signaling complexes that inhibits TRAF2-mediated NF-kappaB activation. J. Exp. Med. 185, 1275-1285 (1997).

43. Regamey, A. et al. The tumor suppressor CYLD interacts with TRIP and regulates negatively nuclear factor kappaB activation by tumor necrosis factor. J. Exp. Med. 198, 1959-1964 (2003).

44. Zhang, M. et al. TRAF-interacting protein (TRIP) negatively regulates IFNbeta production and antiviral response by promoting proteasomal degradation of TANK-binding kinase 1. J. Exp. Med. 209, 1703-1711 (2012).

45. Park, E. S. et al. Tumor necrosis factor (TNF) receptor-associated factor (TRAF)-interacting protein (TRIP) negatively regulates the TRAF2 ubiquitindependent pathway by suppressing the TRAF2-sphingosine 1-phosphate (S1P) interaction. J. Biol. Chem. 290, 9660-9673 (2015).

46. Jacobs, M. D. \& Harrison, S. C. Structure of an IkappaBalpha/NF-kappaB complex. Cell 95, 749-758 (1998).

47. Nelson, D. E. et al. Oscillations in NF-kappaB signaling control the dynamics of gene expression. Science 306, 704-708 (2004).

48. Murphy, S. H. et al. Tumor suppressor protein (p)53, is a regulator of NFkappaB repression by the glucocorticoid receptor. Proc. Natl Acad. Sci. USA 108, 17117-17122 (2011)

49. Webster, G. A. \& Perkins, N. D. Transcriptional cross talk between NFkappaB and p53. Mol. Cell Biol. 19, 3485-3495 (1999).

50. Bonizzi, G. et al. Activation of IKKalpha target genes depends on recognition of specific kappaB binding sites by RelB:p52 dimers. EMBO J. 23, 4202-4210 (2004).

51. Hoffmann, A., Levchenko, A., Scott, M. L. \& Baltimore, D. The IkappaB-NFkappaB signaling module: temporal control and selective gene activation. Science 298, 1241-1245 (2002).

52. Bunz, F. et al. Requirement for p53 and p21 to sustain G2 arrest after DNA damage. Science 282, 1497-1501 (1998).

53. Vince, J. E. et al. TRAF2 must bind to cellular inhibitors of apoptosis for tumor necrosis factor (tnf) to efficiently activate $\mathrm{nf}-\{\mathrm{kappa}\} \mathrm{b}$ and to prevent tnf-induced apoptosis. J. Biol. Chem. 284, 35906-35915 (2009).

54. Li, S., Wang, L. \& Dorf, M. E. PKC phosphorylation of TRAF2 mediates IKKalpha/beta recruitment and K63-linked polyubiquitination. Mol. Cell 33, $30-42$ (2009)

55. Krug, L. M. et al. Vorinostat in patients with advanced malignant pleural mesothelioma who have progressed on previous chemotherapy (VANTAGE014): a phase 3, double-blind, randomised, placebo-controlled trial. Lancet Oncol. 16, 447-456 (2015).

56. Walerych, D. et al. Proteasome machinery is instrumental in a common gainof-function program of the p53 missense mutants in cancer. Nat. Cell Biol. 18, 897-909 (2016).

57. Di Minin, G. et al. Mutant p53 reprograms TNF signaling in cancer cells through interaction with the tumor suppressor DAB2IP. Mol. Cell 56, 617-629 (2014).

58. Gulati, A. P. et al. Mutant human tumor suppressor p53 modulates the activation of mitogen-activated protein kinase and nuclear factor-kappaB, but not c-Jun N-terminal kinase and activated protein-1. Mol. Carcinog. 45, 26-37 (2006).

59. Kato, S. et al. Understanding the function-structure and function-mutation relationships of p53 tumor suppressor protein by high-resolution missense mutation analysis. Proc. Natl Acad. Sci. USA 100, 8424-8429 (2003).

60. Butler, J. S. \& Loh, S. N. Zn(2+)-dependent misfolding of the p53 DNA binding domain. Biochemistry 46, 2630-2639 (2007).

61. Gu, W. \& Roeder, R. G. Activation of $\mathrm{p} 53$ sequence-specific DNA binding by acetylation of the p53 C-terminal domain. Cell 90, 595-606 (1997).

62. Tang, Y., Zhao, W., Chen, Y., Zhao, Y. \& Gu, W. Acetylation is indispensable for p53 activation. Cell 133, 612-626 (2008).

63. Yi, Y. W. et al. Targeting mutant $\mathrm{p} 53$ by a SIRT1 activator YK-3-237 inhibits the proliferation of triple-negative breast cancer cells. Oncotarget 4, 984-994 (2013). 
64. Andrieu, G., Belkina, A. C. \& Denis, G. V. Clinical trials for BET inhibitors run ahead of the science. Drug Disco. Today Technol. 19, 45-50 (2016).

65. Freed-Pastor, W. A. \& Prives, C. Mutant p53: one name, many proteins. Genes Dev. 26, 1268-1286 (2012).

66. Turrell, F. K. et al. Lung tumors with distinct p53 mutations respond similarly to 53 targeted therapy but exhibit genotype-specific statin sensitivity. Genes Dev. 31, 1339-1353 (2017).

67. Kong, L. R. et al. MEK inhibition overcomes cisplatin resistance conferred by SOS/MAPK pathway activation in squamous cell carcinoma. Mol. Cancer Ther. 14, 1750-1760 (2015).

68. Khoury, G. A., Thompson, J. P., Smadbeck, J., Kieslich, C. A. \& Floudas, C. A. Forcefield_PTM: Ab initio charge and AMBER forcefield parameters for frequently occurring post-translational modifications. J. Chem. Theory Comput. 9, 5653-5674 (2013).

69. Chua, K. N. et al. A cell-based small molecule screening method for identifying inhibitors of epithelial-mesenchymal transition in carcinoma. PLoS ONE 7, e33183 (2012).

\section{Acknowledgements}

We thank Pieter Eichhorn for providing the expression vectors for this study. This work was funded to Boon-Cher Goh by the Singapore Ministry of Health's National Medical Research Council, the National Research Foundation Singapore and the Singapore Ministry of Education under its Research Centres of Excellence initiatives. S.K. and C.S.V. thank A*STAR (including an Industry Alignment Pre-Positioning Grant for the Peptide Engineering Program; grant IDs H17/01/a0/010, IAF111213C) and National Supercomputing Centre Singapore for their support.

\section{Author contributions}

Conceptualization, L.R.K., C.F.C., and B.C.G.; Methodology, L.R.K., R.W.O., G.P., M.L., S.K., C.S.V., D.P.L., H.T.H., and C.F.C.; Software, T.Z.T., J.V.C., and L.Y.J.K.; Validation, L.R.K.; Formal analysis, L.R.K., T.Z.T., J.V.C., and L.Y.J.K.; Investigation, L.R.K., R.W.O., T.Z.T., N.A.B.M.S., M.T., J.A.L., and T.B.U.L.; Resources, G.P., W.J.C., D.P.L., H.T.H., C.F.C., and B.C.G.; Data Curation, L.R.K., T.Z.T., S.K., C.S.V., and L.Y.J.K.; Writing Original Draft, L.R.K. and B.C.G.; Writing-Review ānd Editing, L.R.K., L.W., M.L., W.J.C., C.S.V., A.V., C.F.C., and B.C.G.; Visualization, L.R.K., M.L., A.V., and C.F.C.; Supervision, B.C.G.; Project Administration, L.R.K. and B.C.G.; Funding acquisition, B.C.G.

\section{Competing interests}

S.K. and C.S.V are the founders of Sinopsee Therapeutics, a biotech company developing molecules for therapeutic purposes. The remaining authors declare no competing interests.

\section{Additional information}

Supplementary information is available for this paper at https://doi.org/10.1038/s41467020-15608-y.

Correspondence and requests for materials should be addressed to L.R.K. or B.C.G.

Peer review information Nature Communications thanks the anonymous reviewer(s) for their contribution to the peer review of this work. Peer reviewer reports are available.

Reprints and permission information is available at http://www.nature.com/reprints

Publisher's note Springer Nature remains neutral with regard to jurisdictional claims in published maps and institutional affiliations. (c) Open Access This article is licensed under a Creative Commons
Attribution 4.0 International License, which permits use, sharing, adaptation, distribution and reproduction in any medium or format, as long as you give appropriate credit to the original author(s) and the source, provide a link to the Creative Commons license, and indicate if changes were made. The images or other third party material in this article are included in the article's Creative Commons license, unless indicated otherwise in a credit line to the material. If material is not included in the article's Creative Commons license and your intended use is not permitted by statutory regulation or exceeds the permitted use, you will need to obtain permission directly from the copyright holder. To view a copy of this license, visit http://creativecommons.org/ licenses/by/4.0/.

(C) The Author(s) 2020 